\title{
Maternal Drinking During Pregnancy: Attention and Short-Term Memory in 14-Year-Old Offspring- A Longitudinal Prospective Study
}

\author{
Ann P. Streissguth, Paul D. Sampson, Heather Carmichael Olson, Fred L. Bookstein, Helen M. Barr, \\ Mike Scott, Julie Feldman, and Allan F. Mirsky
}

\begin{abstract}
A large and compelling experimental literature has documented the adverse impact of prenatal alcohol exposure on the developing brain of the offspring. This is the first report of adolescent attention/ memory performance and its relationship with prenatal alcohol exposure in a population-based, longitudinal, prospective study ( $n=$ 462) involving substantial covariate control and "blind" examiners. Prenatal alcohol exposure was significantly related to attention/ memory deficits in a dose-dependent fashion. A latent variable reflecting 13 measures of maternal drinking was correlated 0.26 with a latent variable representing 52 scores from 6 tests measuring various components of attention and short-term memory pertormance. The number of drinks/occasion was the strongest alcohol predictor. Fluctuating attentional states, problems with response inhibition, and spatial learning showed the strongest association with prenatal alcohol exposure. A latent variable reflecting the pattern of attention/memory deficits observed at 14 years correlated 0.67 with a composite pattern of deficits previously detected on neurobehavioral tests administered during the first 7 years of life. The 14-year aftention/memory deficits observed in the present study appear to be the adolescent sequelae of deficits observed earlier in development. As is usual in such studies, not all exposed offspring showed deficits.
\end{abstract}

Key Words: Fetal Alcohol Effects, Behavioral Teratology, Alcohol, Adolescent Development, Attention.

$\mathbf{P}$ RENATAL ALCOHOL EXPOSURE has been shown to relate to a wide variety of offspring effects in several fields of study. Its effects have been documented in experimental animal studies where dose and environment are well controlled, and in clinical studies of patients with fetal alcohol syndrome (FAS). Prenatal alcohol effects have also been found in epidemiologic studies where design features and statistical procedures are used to adjust for potentially confounding influences. Until now, the population-based studies have been confined to the pe-

From the Departments of Psychiatry and Behavioral Sciences (A.P.S., H.C.O., H.M.B.), Statistics (P.D.S.), and Psychology (M.S., J.F.), University of Washington, Seattle Washington; Center for Human Growth and Development, University of Michigan (F.L.B.), Ann Arbor, Michigan; and the Laboratory of Psychology and Psychopathology, National Institute of Mental Health (A.F,M.), Bethesda, Maryland.

Received for publication November 28, 1992; accepted July 28, 1993

This research was supported primarily by Grant AA01455-01-18 from the National Institute on Alcohol Abuse and Alcoholism, U.S. Public Health Service.

Reprint requests: Ann P. Streissguth, Ph.D., Fetal Alcohol and Drug Unit, Department of Psychiatry and Behavioral Sciences, GG-20, University of Washington Medical School, Seattle, WA 98195.

Copyright (C) 1994 by The Research Society on Alcoholism. riods of infancy and childhood. This study extends the epidemiologic research on prenatal alcohol effects into the adolescent years and compares the findings to those from recent experimental and clinical studies. We present the first report on the 14-year wave of data collection from the Seattle Longitudinal Study on Alcohol and Pregnancy, ongoing since 1974, involving a birth cohort of close to 500 children whose alcohol exposure histories were documented prenatally.

The long-term behavioral consequences of prenatal alcohol exposure have already been demonstrated in experimental studies of laboratory animals, ${ }^{1}$ and the comparability of these findings to those from earlier human studies has been described. ${ }^{2}$ Several recent reviews of the experimental animal literature have now documented the substantial impact of prenatal ethanol on the developing central nervous system (CNS).$^{3-8}$ A causal link of prenatal alcohol with hippocampal damage and memory deficits in adult animals ${ }^{6-10}$ is in accordance with this study's focus on memory and attentional deficits in humans exposed to varying alcohol doses prenatally.

The possibility that attentional and memory problems in young adolescents could be related to subtle forms of prenatal brain damage from alcohol has not previously been investigated. To date, studies have shown prenatal alcohol effects on habituation and information processing in infants, ${ }^{11,12}$ on attentional problems in preschool children, ${ }^{13,14}$ and on school-age children assessed in the laboratory or classroom. ${ }^{15-17}$ Although not all studies have reported positive findings (e.g., refs. 18 and 19), alcohol teratogenesis in these persistent developmental domainsattention, memory, and information processing-remains of interest across the lifespan. The objective of the present study is to examine the relationship of prenatal alcohol exposure to objective measures of attention and shortterm memory performance assessed in 14-year-old offspring, taking into consideration the potential influences of appropriate covarying conditions that might also predict these outcomes. Neurobehavioral outcomes are of great interest in the study of "low-dose" teratogenic effects, because they are often produced at lower exposure levels than growth and morphologic effects. ${ }^{20}$

\section{METHODS}

The Seattle Longitudinal Prospective Study on Alcohol and Pregnancy began in 1974 with interviews of a population-based group of 1529 
pregnant women from whom a follow-up cohort of $\sim 500$ infants was selected to examine the long-term effects of varying levels of prenatal alcohol exposure. Full details are available elsewhere. ${ }^{21,22}$

\section{Study Design and Rationale}

During a 1-year interval in 1974-1975, all women in prenatal care by the 5th month of pregnancy at two Seattle hospitals were asked to participate in a study of health practices during pregnancy that related to healthy children. The hospitals together reflected the sociodemographic characteristics of the Seattle area.

Cohort selection was made at delivery based on the self-report data for alcohol and cigarettes obtained at the screening interview. The cohort was oversampled for heavier drinkers and smokers. For this stratification, a complex hierarchy of subject selection criteria was developed, ${ }^{22}$ based on an a priori ranking of maternal drinking patterns according to presumed risk to the fetus (as we understood it in 1974). These criteria assured that most of the infants of the "heavier" drinking mothers were scheduled for newborn examinations, but also that balanced proportions of infants born to abstainers and infrequent drinkers were also scheduled. No newborn criteria (except singleton births) entered into the selection process; infants in intensive care were slated for examination along with all other infants as they were well enough to be tested.

As hospital testing of neonates at birth was restricted to two newborns/ day, additional eligible subjects were added at subsequent exam ages. Figure 1 (described later) shows how stratification of the follow-up cohort for smoking by alcohol categories and for maternal education by alcohol categories modified the screening study characteristics to accomplish the teratologic goals of the study. Children missed for testing at one followup were sometimes successfully tested at a subsequent age. Four hundred and five families participated at 4 years and 7 years and 14 years.

Mothers of the children in the present study were predominantly White (88\%), married (87\%), and middle class $(81 \%)$, and averaged 26 years of age and 13.7 years of education at the time of interview. They were "low risk" by conventional pregnancy outcome criteria, even though these criteria were not used in cohort selection. For example, in the cohort, the prematurity rate was low (only $4 \%<37$ weeks), as was the low-birth weight rate (only $3 \%<2500 \mathrm{~g}$ ). At 7 years of age, $95 \%$ of the children still lived with their biologic mothers and $70 \%$ with their biologic fathers. The cohort thus included a large number of offspring who were simultaneously at relatively high risk for alcohol effects and at relatively low risk for other competing causes of poor developmental outcome.

\section{Prenatal Alcohol Exposure: Assessment and Categorization}

Alcohol exposure was measured by maternal report in the 5th month of pregnancy. ${ }^{22}$ Many different patterns of alcohol use were documented to investigate those most salient (influential) for predicting adverse outcomes. Quantity-frequency-variability (QFV) questions assessed the consumption of beer, wine, and liquor for two time periods: during pregnancy and prepregnancy recognition (the month or so prior to pregnancy or pregnancy recognition). The "pre" scores are particularly important, because the typical decrease of alcohol use after recognition of pregnancy comes too late to protect the embryo during the earliest window of potential teratogenic effects.

The primary alcohol scores are presented in Table 1, where their distributions (for drinkers only) are summarized. We generated a variety of alcohol scores incorporating aspects of level, pattern, and timing of exposure because when this study began there was no information available on which alcohol variables might be critical to offspring effects. Average ounces of absolute alcohol (AA) consumed/day reflects the overall level of exposure. An AA score of 1.0 represents average consumption of about two drinks/day, but the pattern of consumption might be a regular daily drinking pattern or an infrequent binge.

Several scores were calculated to clarify the effects of "massed" drinking patterns. The "BINGE" score is dichotomous, representing subjects who reported drinking 5 or more drinks on any occasion in the time period in question. MAX (maximum drinks any occasion) and ADOCC (average drinks/occasion) are counts of the maximum and average drinks/occasion, respectively, reported in the given time period. The QFV score is a scheme for averaging both daily and massed drinking. The monthly occasions score (MOCC) is a simple frequency count of drinking occasions. An ORDEXC [Ordered Exposure Categories (from $0=$ none to $4=$ high)] was developed at the outset of the study to select infants for the follow-up component based on an ordering of all the alcohol scores according to what we presumed in 1974 to be their greatest risk to the fetus. For further details on alcohol scores, see Table 1 (especially the note) and refs. 21 and 22 .

As most of these alcohol scores have highly skewed distributions with relatively few extreme cases, AA, MAX, ADOCC, and MOCC were initially $\log$-transformed to reduce the effect of outliers in descriptive analyses. For any monotone transformations of these scores likely to be considered in practice, there remains far too much collinearity for these scores to be used as joint predictors in multiple regression analyses. Even after log-transformation, the correlations among the 13 predictors range from 0.39 to 0.97 . In such situations, the Partial Least Squares (PLS) procedure is both more conservative and more powerful than other alternatives, such as selecting the "best" predictor for each outcome. In our implementation of this procedure, rather than relying on logtransforms, the 13 scores were nonparametrically transformed by calibrating each against the net outcome in an iterative algorithm as described below.

In this study, "heavier" drinker is used informally to describe the women at the higher end of various alcohol-use self-report scales. In selecting the follow-up cohort at delivery, top priority was given to infants of mothers who had an AA score of 1.00 or higher (roughly 2 drinks/day of wine, beer, or liquor) (see ref. 22 for full details). The next highest priority of "heavier" drinker were women who were missed by the AA criteria, but who had volume variablity (VV) ${ }^{80}$ scores of 8 or 11 (indicating report of 5 or more drinks on some occasion). These AA criteria and VV criteria together constituted the ORDEXC $=4$ category (highest priority drinkers for scheduling infants). This prioritized concept of "heavier" drinker enabled recruitment of almost all of the infants of the "heavier" drinking mothers from the entire screening sample of 1529 , for a manageable cohort of 500 offspring maintaining virtually all the power of the larger sample to detect alcohol effects. Figure 1 depicts the impact of this sampling procedure on the "heavier" drinking end of the continuum. A special effort was made to select not only infants of abstainers, but also infants born to women whom we informally termed "infrequent" drinkers. This category was defined not only by an overall AA score of $\leq 0.10 \mathrm{oz}$, but also by the absence of any of the criteria for "heavier" drinking-i.e., VV 5-8-11 (ever reporting 5 or more drinks on any occasion in either time period). This kept the low end of the alcohol distribution free of occasional heavy binge drinkers (i.e., women who may have only drunk once during pregnancy, but who had a major binge on this one occasion).

This basically middle-class cohort represents a broad range of alcohol exposures, including abstainers. The overall mean AA score for the subjects comprising the 14-year follow-up cohort is 0.59 (a little over 1 drink/day), with a median of $0.12(<1 / 2 \mathrm{drink} /$ day) for the prepregnancy recognition period, and a mean of 0.25 ( $1 / 2 \mathrm{drink} /$ day $)$, with median 0.05 for the midpregnancy period. Approximately $73 \%$ of the mothers were drinking at the outset of pregnancy, and $78 \%$ were drinking at the 5 th month. (Table 1 presents distributions on all alcohol scores, calculated for drinkers only.)

\section{Other Exposures, Covariates, and Intervening Variables}

In studies of human behavioral teratology, it is essential to assess the potentially confounding effects of other variables that may relate to both alcohol and the outcomes studied. The most important of these potential covariates were assessed during pregnancy (tobacco and caffeine, use of other drugs and medications, and nutrition); others were recorded over the subsequent years of follow-up. ${ }^{21-23}$ 


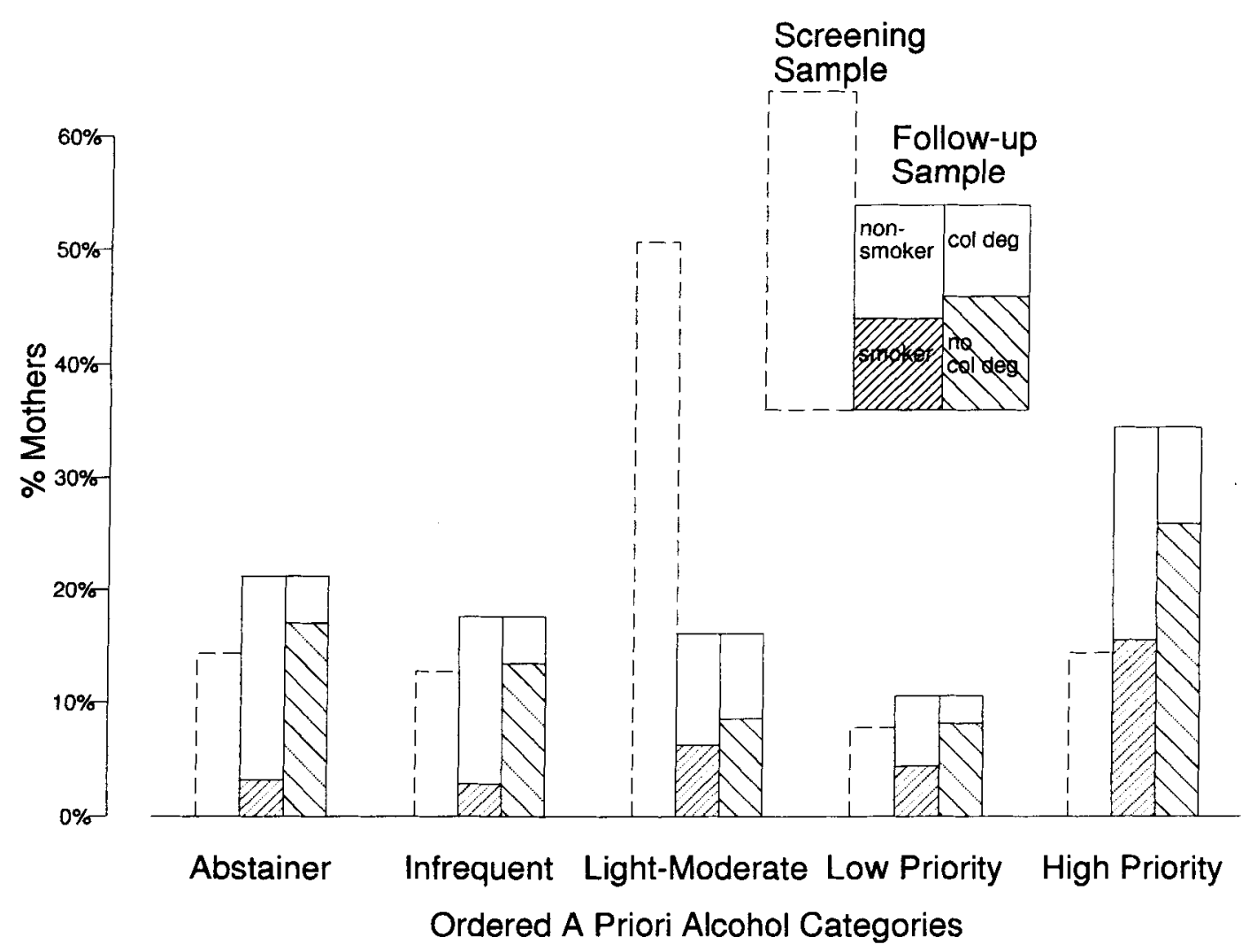

Fig. 1. Alcohol exposure categories as represented in the screening sample and the follow-up sample: stratification by smoking and maternal education. The two

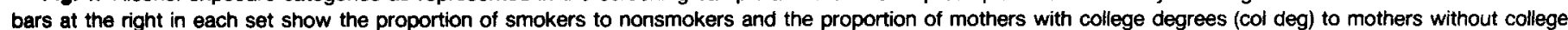

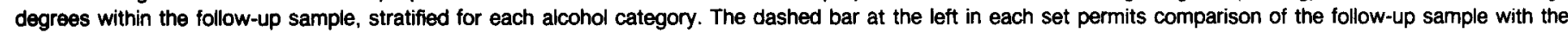

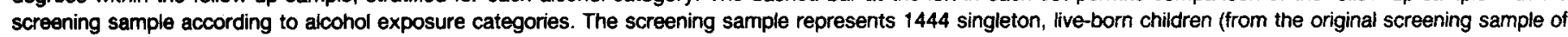

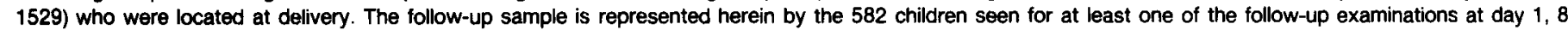

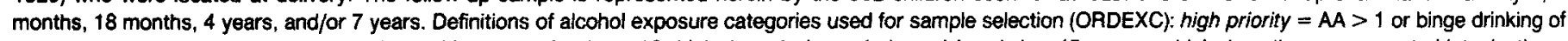

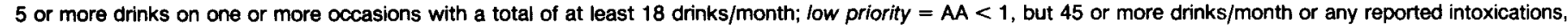

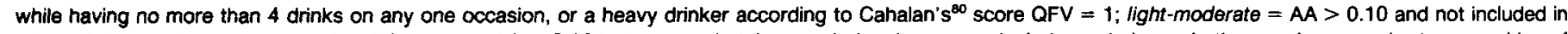

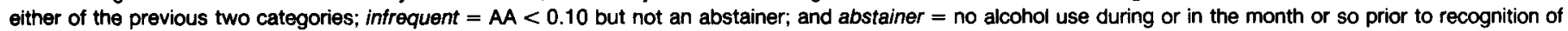
pregnancy. Classification considered alcohol scores for both prepregnancy recognition and during pregnancy. For further details, see Streissguth et al. ${ }^{22}$

Demographic covariates included race, age, education, socioeconomic status (SES), marital status and parity of the mother, education of the father, family income, sex of the child, and exact age of the adolescent at the 14-year exam. Data on postnatal events, obtained at each of the five postnatal examinations, included illnesses, high fevers, accidents, hospitalizations, medical problems, major life changes in the household, etc. Home environment was studied at 12 months with the HOME scale; mother-child interaction was assessed by rating scales filled out by the examiner following the 8- and 18-month exams. Data on situational factors that could have affected performance on the test battery were also studied. These included minor illness on the day of the exam, medications and or alcohol/drug use prior to exam, and access to computer games. Sensory problems were also considered as possible covariates (see "General Procedures"). Altogether over 150 potential covariates were measured and considered as potential confounders. See "PLS Statistical Analysis" for how covariates were examined in the present study: ref. 23 includes a more detailed description and rationale.

\section{Subjects}

Contact was maintained with the sample through annual birthday card mailings and other outreach activities developed in our laboratory. ${ }^{24}$ The 464 participants in the 14-year exam represented an $82 \%$ follow-up of the original birth cohort. There was not a significantly greater loss to follow-up of children of heavier drinkers compared with the rest of the cohort; $93 \%$ of the subjects seen at the 7 -year exam were evaluated again at 14 years. Four hundred sixty-two subjects ( 247 boys and 215 girls) had valid attention/memory tests. [The two with missing data included one, who could not come to the lab for tests, but completed interview data and one who refused to watch the Continuous Performance Test (CPT) screen.] At testing, subjects ranged in age from 13.9 to 15.7 years, with a mean of 14.4 years. Adjustments for differences in age were included in the analyses as appropriate.

\section{General Procedures for the 14-Year Examination}

Subjects were examined at a special laboratory at the University of Washington. Many precautions were taken to avoid bias and obtain valid tests in a standard fashion. All scheduling of appointments and tracing of subjects was conducted by an outreach worker. Examiners had no contact with the families and no knowledge of results of earlier examinations or prenatal exposures. Examiners were graduate students or college graduates in psychology, trained to a high degree of reliability maintained by occasional reliability checks. The Attention/Memory Battery described in this study was part of a single testing session lasting $4 \mathrm{hr}$ (including two scheduled breaks). Additional reports on other components of the battery are underway (e.g., ref. 25).

The examiner coded each test for validity; all questionable tests were reviewed "blind" before being entered into the database. Beyond these deletions, sample sizes vary somewhat across tests owing to changes of format over time and to occasional procedural failures. To verify that the findings were not confounded with sensory impairment, subjects 
Table 1. Alcohol Use During Pregnancy: Summary Statistics for Drinkers Only

\begin{tabular}{|c|c|c|c|c|c|c|}
\hline & $n$ & Mean & SD & Minimum & Median & Maximum \\
\hline \multicolumn{7}{|l|}{ AA: Average oz AA/day } \\
\hline Prepregnancy recognition & 338 & 0.81 & 1.76 & 0.01 & 0.40 & 25.76 \\
\hline During pregnancy & 359 & 0.32 & 0.59 & 0.01 & 0.16 & 8.55 \\
\hline \multicolumn{7}{|c|}{ MOCC: Monthly occasions of drinking (average) } \\
\hline Prepregnancy recognition & 338 & 16.88 & 22.75 & 0.3 & 9.0 & 240.0 \\
\hline During pregnancy & 359 & 7.98 & 11.55 & 0.3 & 4.5 & 105.3 \\
\hline \multicolumn{7}{|l|}{ QFV: Quantity-Frequency-Variability Index } \\
\hline Prepregnancy recognition & 338 & 3.52 & 1.03 & 2 & 3 & 5.0 \\
\hline During pregnancy & 359 & 3.02 & 0.93 & 2 & 3 & 5.0 \\
\hline \multicolumn{7}{|l|}{ ADOCC: Average drinks/occasion } \\
\hline Prepregnancy recognition & 338 & 2.49 & 1.44 & 1.50 & 2.2 & 13.00 \\
\hline During pregnancy & 359 & 2.17 & 1.14 & 1.50 & 1.7 & 13.00 \\
\hline \multicolumn{7}{|l|}{ MAX: Maximum drinks/any occasion } \\
\hline Prepregnancy recognition & 338 & 4.00 & 2.54 & 1.50 & 3.5 & 13.00 \\
\hline During pregnancy & 359 & 3.60 & 2.58 & 1.50 & 3.5 & 13.00 \\
\hline \multicolumn{7}{|l|}{ BINGE: 5 or more drinks on any occasion } \\
\hline Prepregnancy recognition & 338 & 0.39 & 0.49 & 0 & 0 & 1.0 \\
\hline During pregnancy & 359 & 0.24 & 0.43 & 0 & 0 & 1.0 \\
\hline ORDEXC: ordered exposure categories & 368 & 2.79 & 1.22 & 1 & 3.0 & 4.0 \\
\hline
\end{tabular}

Note: A high score indicates "more drinking" for all measures (the QFV scores have been reversed to make them compatible in direction with the other alcohol scores). Some profiles of the "typical" drinker in this study follow, based on the median score for drinkers only. An AA score of 1.00 is equivalent to $\sim 30 \mathrm{~g}$ of alcohol/day or two "drinks"/day of beer, or wine, or liquor. An AA of 0.40 indicates that the typical drinker in this study drank 1 drink of wine, beer and/or liquor a day on average prior to pregnancy recognition. An AA of 0.16 is $<1 / 2$, a drink a day, on average, during pregnancy. A MOCC score of 9 indicates that the typical drinker in this study drank on 9 occasions/month, on average. An ADOCC score of 2.5 indicates that the typical drinker in this study reported $2 \frac{1}{2}$ drinks of wine, beer, or liquor on average whenever she drank prior to pregnancy recognition. She reported $<2$ drinks on average when she drank during pregnancy. A MAX score of 3.5 indicates that the typical drinker in this study reported $3 \frac{1}{2}$ drinks on at least one occasion during the designated time period. A BINGE score of 0 indicates that the typical drinker in this study never reported 5 or more drinks on an occasion. Thirty-nine percent of the mothers who drank had at least 5 or more drinks on at least one occasion prior to pregnancy recognition and $24 \%$ had this pattern during pregnancy. Sample size varies because Table 1 includes only those mothers who reported drinking during the designated time period. The statistics for "pre" (prepregnancy recognition) omit 124 mothers who abstained during that period. The "during" pregnancy statistics omit 103 mothers who abstained during pregnancy. The ORDEXC statistics omit 94 mothers who abstained during both time periods (total sample size for study is 462 ). Scores in this table are untransformed for comparative purposes even though transformed scores (as noted in the text) were used in analysis.

were tested for visual acuity, visual accommodation, and color blindness. Hearing acuity was evaluated informally and from self- and parental report. Subjects were tested with glasses if they customarily wore them. Covariates, as well as additional outcomes not reported herein, were gathered by interview and questionnaire from parents and subjects.

\section{Attention/Memory Battery}

The battery described in this study included four tests measuring aspects of attention and two assessing aspects of short-term memory. Full details are available on request.

The selection of attention tests was based on the principle that attention is not a unitary skill or capacity, but consists of a number of separable factors or elements. One conceptualization of this articulated view of attention is provided by Mirsky and colleagues, ${ }^{26-28}$ who have described four separate elements of attention (encode, shift, focus, and sustain). These were identified on the basis of principal component analysis of neuropsychological test scores from two populations of subjects: 203 adults and 435 children. ${ }^{26}$ The factor structure revealed by this analysis has been replicated in a number of independent populations. ${ }^{26}$

The attention tests selected for the present study and the putative elements sampled by them include the following: the Digit Span Subtest from the Wechsler Intelligence Scale for Children-Revised (WISC-R), ${ }^{29}$ a measure of encoding 26 ; the Wisconsin Card Sorting Test, a concept identification task, ${ }^{30,31}$ and a measure of the ability to shift attention, ${ }^{26}$ as well as of frontal lobe dysfunction ${ }^{32}$; the Talland Letter Cancellation Test, a perceptual-motor speed accuracy paper and pencil task, ${ }^{33}$ and a measure of the ability to focus attention on a task and screen out distraction $\mathrm{s}^{26}$; and the CPT, a vigilance test ${ }^{34}$ and a measure of the ability to sustain a focus of attention over time..$^{26,34-36}$ As used herein, the CPT had a 4.2-min X-task, an 8.6-min AX-task, and a 5.5-min DX-task involving degraded stimuli via a ground-glass color monitor and a Zenith Z-286LP computer programmed for the National Institute of Mental Health (NIMH) Attention Battery. ${ }^{27}$ CPT vigilance has been used exten- sively in the assessment of children with disordered attention and as a method to evaluate the efficacy of stimulant drugs. ${ }^{37}$

The short-term memory tests included the Seashore Rhythm Test ${ }^{38}$ and the Stepping Stone Maze ${ }^{39}$ first used by Milner to detect memory deficits in patients with hippocampal lesions. Our version was programmed for an Apple IIe computer with a color monitor and involved finding (with appropriate feedback) an invisible path through a "short" $(4 \times 6)$ matrix of squares and then a "long" $(8 \times 8)$ matrix. Thus, shortterm memory was assessed in both auditory and spatial modalities, with simple auditory patterns on the Seashore Rhythm Test, and with a complex spatial pattern on the Stepping Stone Maze.

Three of the tests in the battery (CPT, Digit Span, and Seashore Rhythm) reflected significant effects of maternal alcohol consumption when these subjects were 7 years of age. ${ }^{40-42}$ The Stepping Stone Maze was included because it has been found to reflect significant impairment in spatial memory in noncohort patients with FAS examined in our laboratory ${ }^{43}$ and because the spatial aspects of this particular maze task were similar to those successfully used by animal researchers to detect alcohol-related memory deficits in rat offspring. ${ }^{6,44}$

Order of testing was as follows: WISCONSIN, TALLAND, SEASHORE, DIGITS, MAZE, and CPT. Descriptive statistics for the 52 outcome scores deriving from these six primary tests appear in Table 2. As there was no a priori method for predicting ahead of time which scores would be the most sensitive to prenatal alcohol exposure in 14year-old offspring, all the usual scores for each test were evaluated. The large battery of tests and scores permitted evaluation of which tests (as reflected in the domains of behavior examined) and which actual scores (as reflected in the type of errors or problems encountered) best detected the 14-year consequences of prenatal alcohol exposure on attention/ memory performance. Table 2 presents mean standard scores (z-scores) for each of the outcomes within categories of a representative alcohol score. Except in Table 2, long-tailed outcome scores were log-transformed before PLS analysis to increase the precision with which saliences and latent variable (LV) scores could be estimated. 
Table 2. 14-Year Attention/Memory Battery: Descriptive Statistics

\begin{tabular}{|c|c|c|c|c|c|c|c|}
\hline \multirow[b]{2}{*}{ Tests and scores } & \multirow[b]{2}{*}{$n$} & \multirow[b]{2}{*}{ Mean } & \multirow[b]{2}{*}{ SD } & \multirow[b]{2}{*}{ Minimum } & \multirow[b]{2}{*}{ Maximum } & \multicolumn{2}{|c|}{$\begin{array}{c}\text { Alcohol exposure } \\
\text { (mean Z-scores: signed) }\end{array}$} \\
\hline & & & & & & $\begin{array}{l}\text { No binge } \\
(n=318)\end{array}$ & $\begin{array}{c}\text { Binge } \\
(n=144)\end{array}$ \\
\hline \multicolumn{8}{|l|}{ Continuous Performance Test (CPT) } \\
\hline SDRT $-\mathrm{X}$ & 457 & 0.08 & 0.03 & 0.04 & 0.17 & -0.09 & 0.21 \\
\hline SDRT-AX & 446 & 0.10 & 0.04 & 0.03 & 0.29 & -0.06 & 0.09 \\
\hline SDRT-DX & 442 & 0.12 & 0.04 & 0.06 & 0.33 & -0.07 & 0.14 \\
\hline False Alarms-AX* & 446 & 10.19 & 19.42 & 0.00 & 134.00 & -0.04 & 0.09 \\
\hline Ratio False Alarms/Total Presses-AX & 446 & 0.10 & 0.16 & 0.00 & 0.86 & -0.03 & 0.07 \\
\hline Mean Reaction Times-DX & 442 & 0.61 & 0.07 & 0.36 & 0.85 & -0.00 & 0.03 \\
\hline Mean Reaction Times-X & 457 & 0.42 & 0.05 & 0.31 & 0.59 & -0.02 & 0.08 \\
\hline False Alarms-DX* & 442 & 10.82 & 17.59 & 0.00 & 175.00 & -0.02 & 0.05 \\
\hline Errors of Omission-AX* & 446 & 7.44 & 12.08 & 0.00 & 70.00 & -0.01 & 0.03 \\
\hline Ratio False Alarms/Total Presses-DX* & 442 & 0.16 & 0.17 & 0.00 & 0.86 & -0.02 & 0.05 \\
\hline False Alarms- $X^{*}$ & 457 & 0.90 & 1.57 & 0.00 & 12.00 & 0.01 & -0.04 \\
\hline Errors of Omission- $X^{*}$ & 457 & 0.80 & 2.03 & 0.00 & 29.00 & -0.02 & 0.05 \\
\hline Mean Reaction Times-AX & 446 & 0.34 & 0.06 & 0.21 & 0.58 & -0.00 & 0.03 \\
\hline Ratio False Alarms/Total Presses- $X^{*}$ & 457 & 0.02 & 0.03 & 0.00 & 0.22 & 0.02 & -0.00 \\
\hline Errors of Omission-DX* & 442 & 16.99 & 12.81 & 0.00 & 55.00 & 0.01 & -0.03 \\
\hline \multicolumn{8}{|l|}{ Talland Letter Cancellation (TALLAND) } \\
\hline Total Correct--Both & 456 & 61.04 & 12.30 & 11.5 & 95.5 & -0.09 & 0.21 \\
\hline False Alarms-Capitals* & 460 & 0.96 & 1.42 & 0.0 & 9.5 & -0.08 & 0.18 \\
\hline Total Correct-Spaces & 455 & 64.48 & 13.21 & 5.5 & 101.0 & -0.08 & 0.18 \\
\hline False Alarms--Spaces* & 455 & 0.44 & 1.61 & 0.0 & 26.5 & -0.07 & 0.15 \\
\hline Errors of Omission-Both* & 457 & 4.98 & 5.61 & 0.0 & 57.5 & -0.06 & 0.13 \\
\hline False Alarms-Both* & 457 & 0.80 & 1.98 & 0.0 & 30.0 & -0.04 & 0.09 \\
\hline Total Letters-Spaces & 455 & 323.34 & 66.38 & 42.0 & 553.5 & -0.07 & 0.16 \\
\hline Total Correct-Capitals & 458 & 53.64 & 11.75 & 14.0 & 85.5 & -0.04 & 0.09 \\
\hline Total Letters--Both & 457 & 154.44 & 28.34 & 66.0 & 255.5 & -0.06 & 0.13 \\
\hline Total Letters--Capitals & 460 & 205.52 & 42.03 & 56.0 & 321.0 & -0.05 & 0.12 \\
\hline Errors of Omission-Spaces* & 455 & 5.21 & 6.45 & 0.0 & 59.5 & -0.02 & 0.04 \\
\hline Errors of Omission-Capitals & 460 & 3.91 & 3.76 & 0.0 & 42.5 & 0.00 & -0.00 \\
\hline \multicolumn{8}{|l|}{ Stepping Stone Maze (MAZE) } \\
\hline No. of Trials to First Success_LLong & 450 & 5.38 & 2.02 & 2 & 15 & -0.08 & 0.17 \\
\hline Total Errors-Long" & 450 & 15.58 & 17.34 & 0 & 149 & -0.05 & 0.12 \\
\hline No. of Trials to Criterion-Long* & 450 & 9.68 & 4.40 & 4 & 40 & -0.06 & 0.14 \\
\hline No. of Trials to Criterion-Short* & 450 & 4.42 & 1.45 & 3 & 15 & -0.04 & 0.08 \\
\hline Total Time-Long* & 450 & 3.34 & 1.76 & 0.86 & 11.77 & -0.06 & 0.13 \\
\hline No. of Trials to First Success-Short & 450 & 3.09 & 1.07 & 2 & 8 & -0.02 & 0.06 \\
\hline Total Errors-Short* & 450 & 2.45 & 3.50 & 0 & 32 & -0.02 & 0.04 \\
\hline Reproduction-Long & 450 & 0.12 & 0.38 & 0 & 2 & -0.02 & 0.06 \\
\hline Total Time-Short* & 450 & 0.70 & 0.39 & 0.20 & 3.28 & -0.00 & 0.01 \\
\hline Total Time Last 3 Trials-Long* & 450 & 0.30 & 0.06 & 0.16 & 0.58 & -0.00 & 0.00 \\
\hline Total Successful Trials-Long* & 450 & 4.04 & 1.63 & 0 & 16 & 0.00 & -0.00 \\
\hline Reproduction-Short & 447 & 1.55 & 0.55 & 0 & 2 & 0.01 & -0.04 \\
\hline \multicolumn{8}{|l|}{ Seashore Rhythm (SEASHORE) } \\
\hline Errors-Set B & 459 & 1.13 & 1.35 & 0 & 7 & -0.08 & 0.17 \\
\hline Errors-Set A & 459 & 0.49 & 0.88 & 0 & 9 & -0.04 & 0.10 \\
\hline Errors-Set C & 459 & 2.26 & 1.57 & 0 & 9 & -0.04 & 0.08 \\
\hline No. of Trials Left Blank & 459 & 0.05 & 0.40 & 0 & 6 & -0.01 & 0.00 \\
\hline \multicolumn{8}{|l|}{ Wisconsin Card Sort (WISCONSIN) } \\
\hline Total Categories & 462 & 4.58 & 1.69 & 0 & 6 & -0.09 & 0.20 \\
\hline Other Responses (no.) ${ }^{\star}$ & 462 & 8.03 & 10.19 & 0 & 61 & -0.08 & 0.17 \\
\hline Total Errors & 462 & 39.80 & 20.94 & 8 & 102 & -0.07 & 0.17 \\
\hline Total Correct & 462 & 76.41 & 14.30 & 26 & 105 & -0.06 & 0.12 \\
\hline No. of Trials First Successful Category* & 462 & 21.32 & 22.75 & 10 & 128 & -0.02 & 0.04 \\
\hline Total Failures to Maintain Set & 462 & 1.59 & 1.46 & 0 & 7 & -0.03 & 0.08 \\
\hline \multicolumn{8}{|l|}{ WISC Digit Span (DIGITS) } \\
\hline Digits Backward & 462 & 6.00 & 2.13 & 2 & 13 & -0.06 & 0.13 \\
\hline Digit Span Scaled Score & 461 & 9.28 & 2.73 & 2 & 18 & -0.05 & 0.12 \\
\hline Digits Forward & 462 & 7.22 & 2.14 & 2 & 13 & -0.03 & 0.05 \\
\hline
\end{tabular}

- Denotes scores that were log-transformed for analysis. (The descriptive statistics presented in this table are for untransformed scores.) Reaction times are presented

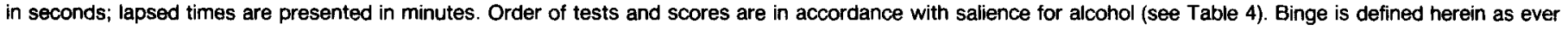

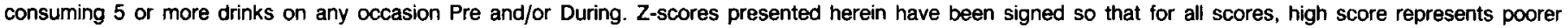
performance. 


\section{PLS STATISTICAL ANALYSIS}

These data were analyzed by a multivariate technique, nonlinear PLS, that has been developed and used in earlier analyses from this study. ${ }^{17,21,41,42,45}$ For a survey of other applications of PLS, see ref. 46. This methodology is ideal for examining the central teratological concern of our study, the dose-response relationship between prenatal alcohol exposure and offspring attention/memory performance at age 14 years. Briefly, the PLS approach combines all the measures of alcohol exposure into one "composite dose measure," called the Alcohol $L V$, and combines all the outcome measures into a composite outcome measure called a net Attention/Memory LV. PLS analysis determines which of the alcohol scores are most salient (influential) in predicting adverse outcomes, and which of the 52 outcomes are most salient (influential) for the teratogenic effects of alcohol. This procedure for quantitating alcohol effects on outcomes is preferable to multiple regression, in which adding or deleting predictor variables can drastically alter coefficients of other predictors and make findings unreliable across analyses within a study and across studies. In PLS analyses, coefficients are far more robust against changes in the list of predictors ${ }^{47}$ and also against resampling of cases in the data set. Canonical correlations analysis is sometimes used for reducing the number of predictors. It is less desirable than PLS herein, because although canonical correlations analysis reflects the internal factor structure of either block separately, the coefficients do not actually represent the importance (salience) of individual measures for the predictions from alcohol to outcomes. ${ }^{21,41}$ It is the rank-order of these saliences that is our primary empirical interest.

Following a PLS analysis, permutation techniques may be used to examine statistical significance of the PLS analyses, and covariates can be examined using multiple regression techniques to check potentially competing hypotheses (i.e., that the effects were produced by something other than alcohol). Finally, a longitudinal path model was developed to examine the relationship of 14-year attention/memory performance to measured neurobehavioral performance throughout the first 7 years of life.

Because PLS is a relatively new procedure not familiar to many of our readers, we present a more detailed statistical description than would otherwise be necessary. The reason PLS is the statistical methodology of choice for the question addressed herein is that it has a more relevant rationale for the combination of variables than principal components analysis, canonical correlation, or any other brand of factor analysis. (Software in S-PLUS ${ }^{48,49}$ is available from the authors.) PLS not only deals comfortably with any number of outcomes (herein attention/memory performance), but also any number of measures of the predictor (herein prenatal alcohol), and any number of subjects. PLS permits the investigator to deal with multiple predictors and multiple outcomes without violating the warnings against multiple tests inherent in most multivar- iate techniques. The LV correlations reported are not spurious or artifacts of the PLS methodology -in fact, the method is actually more conservative than what a canonical correlation on these data would report (i.e., the reported correlation is lower and more stable against substitution of predictors). Yet the main reason we use PLS is not that it is more conservative or easier to calculate; it is because this statistical methodology best suits the questions we ask, questions about the relation of alcohol dose to the outcome battery as a whole. This study was conducted not to detect the single best neurobehavioral test of prenatal alcohol exposure, but rather to study the pervasive impact of exposure on a broad range of performance measures.

The calculation centers around the $13 \times 52$ matrix of correlations (Table 3) between the 13 alcohol scores and the 52 attention/memory scores. In PLS the LVs are the pair of linear combinations (of measures of dose and outcome respectively) of maximal covariance, not maximal correlation (as in multiple regression, canonical correlations, etc.) and not joint likelihood (as in LISREL). When the composites are computed in this way, the coefficient of each variable serves as a salience, representing its weight in the composite as well as its importance in the cross-block analysis. That is, saliences for the alcohol variables are proportional to their correlations with the outcome LV (the composite outcome score), and those for the outcome variables are proportional to their correlations with the Alcohol LV (the composite dose score). After these saliences are interpreted, scatterplots of the LV scores and the items are examined for outliers and nonlinearities, and the correlation between the LVs is adjusted to evaluate the degree to which the relationship could be attributable to covariates rather than to alcohol exposure per se. Reference 21 expands on this section and offers a great many additional explanations.

All of this can be expressed algebraically as follows. The Alcohol LV score will be written:

$$
\mathrm{LV}_{\mathrm{A}}=\alpha_{1} \mathrm{~A}_{1}+\ldots+\alpha_{13} \mathrm{~A}_{13}=\sum_{\mathrm{i}=1}^{13} \alpha_{\mathrm{i}} \mathrm{A}_{\mathrm{i}}
$$

where $A_{1}, \ldots, A_{13}$ are the 13 alcohol indicators, scaled to have variance one, and $\alpha_{1}, \ldots, \alpha_{13}$ are 13 weights to be computed. The $\alpha$ 's are to be proportional to the correlations of the A's with a similarly defined weighted sum

$$
L V_{B}=\beta_{1} B_{1}+\ldots+\beta_{52} B_{52}=\sum_{j=1}^{52} \beta_{j} B_{j}
$$

That is,

$$
\begin{gathered}
\alpha_{\mathrm{i}} \propto \operatorname{corr}\left(\mathrm{A}_{\mathrm{i}}, \sum \beta_{\mathrm{j}} \mathrm{B}_{\mathrm{j}}\right) \\
\propto \operatorname{cov}\left(\mathrm{A}_{\mathrm{i}}, \sum \beta_{\mathrm{j}} \mathrm{B}_{\mathrm{j}}\right) \\
=\sum_{\mathrm{j}=1}^{52} \mathrm{r}_{\mathrm{ij}} \beta_{\mathrm{j}}
\end{gathered}
$$


Table 3. Correlations Among Prenatal Alcohol Scores and 14-Year Attention/Memory Scores

\begin{tabular}{|c|c|c|c|c|c|c|c|c|c|c|c|c|c|}
\hline & $\begin{array}{l}\text { AA } \\
\text { pre }\end{array}$ & $\begin{array}{c}\text { AA } \\
\text { during }\end{array}$ & $\begin{array}{l}\text { Binge } \\
\text { pre }\end{array}$ & $\begin{array}{l}\text { Binge } \\
\text { during }\end{array}$ & $\begin{array}{l}\text { ADOCC } \\
\text { pre }\end{array}$ & $\begin{array}{l}\text { ADOCC } \\
\text { during }\end{array}$ & $\begin{array}{l}\text { MAX } \\
\text { pre }\end{array}$ & $\begin{array}{c}\text { MAX } \\
\text { during }\end{array}$ & $\begin{array}{c}\text { MOCC } \\
\text { pre }\end{array}$ & $\begin{array}{l}\text { MOCC } \\
\text { during }\end{array}$ & $\begin{array}{l}\text { QFV } \\
\text { pre }\end{array}$ & $\begin{array}{c}\text { QFV } \\
\text { during }\end{array}$ & ORDEXC \\
\hline CPT SDRT - $X$ & -0.12 & -0.16 & -0.14 & -0.17 & -0.14 & -0.19 & -0.15 & -0.18 & -0.12 & -0.14 & -0.15 & -0.22 & -0.13 \\
\hline CPT SDRT-AX & -0.05 & -0.12 & -0.07 & -0.11 & -0.15 & -0.21 & -0.13 & -0.14 & -0.09 & -0.10 & -0.08 & -0.13 & -0.07 \\
\hline CPT SDRT-DX & -0.10 & -0.10 & -0.12 & -0.10 & -0.16 & -0.11 & -0.15 & -0.08 & -0.09 & -0.06 & -0.15 & -0.15 & -0.12 \\
\hline CPT FA-AX & -0.06 & -0.11 & -0.10 & -0.09 & -0.17 & -0.14 & -0.12 & -0.10 & -0.08 & -0.09 & -0.14 & -0.09 & -0.07 \\
\hline CPT Ratio FA-AX & -0.05 & -0.12 & -0.06 & -0.09 & -0.14 & -0.12 & -0.09 & -0.09 & -0.08 & -0.11 & -0.09 & -0.09 & -0.06 \\
\hline CPT MRT-DX & -0.07 & -0.10 & -0.01 & -0.03 & -0.07 & -0.13 & -0.08 & -0.08 & -0.10 & -0.06 & -0.07 & -0.08 & -0.04 \\
\hline CPT MRT—X & -0.02 & -0.07 & -0.05 & -0.04 & -0.09 & -0.15 & -0.09 & -0.08 & -0.05 & -0.06 & -0.08 & -0.06 & -0.03 \\
\hline CPT FA-DX & -0.05 & -0.04 & -0.03 & -0.06 & -0.10 & -0.06 & -0.07 & -0.04 & -0.06 & -0.02 & -0.08 & -0.07 & -0.06 \\
\hline CPT EO-AX & 0.01 & -0.05 & -0.06 & -0.05 & -0.12 & -0.09 & -0.09 & -0.05 & -0.02 & -0.03 & -0.09 & -0.03 & -0.03 \\
\hline CPT Ratio FA-DX & -0.03 & -0.02 & -0.02 & -0.06 & -0.10 & -0.06 & -0.08 & -0.03 & -0.04 & 0.01 & -0.08 & -0.08 & -0.04 \\
\hline CPT FA-X & -0.05 & -0.08 & -0.03 & -0.05 & -0.05 & -0.05 & -0.03 & -0.05 & -0.05 & -0.07 & -0.04 & -0.07 & -0.05 \\
\hline CPT EO-X & -0.04 & -0.02 & -0.02 & -0.05 & -0.08 & -0.07 & -0.02 & -0.01 & -0.06 & 0.00 & -0.02 & -0.04 & -0.01 \\
\hline СРТ MRT-AX & -0.04 & -0.03 & 0.00 & 0.02 & -0.02 & -0.06 & -0.03 & -0.03 & -0.08 & -0.02 & -0.04 & 0.01 & -0.05 \\
\hline CPT Ratio FA-X & -0.03 & -0.05 & 0.00 & -0.03 & -0.02 & -0.02 & 0.00 & -0.02 & -0.03 & -0.04 & -0.02 & -0.04 & -0.02 \\
\hline CPT EO-DX & 0.06 & 0.03 & 0.04 & 0.00 & -0.02 & 0.00 & -0.02 & 0.04 & 0.03 & 0.09 & -0.02 & 0.00 & 0.10 \\
\hline TALLAND TC-B & 0.08 & 0.08 & 0.13 & 0.18 & 0.18 & 0.20 & 0.17 & 0.17 & 0.09 & 0.06 & 0.16 & 0.17 & 0.10 \\
\hline TALLAND FA-C & -0.09 & -0.09 & -0.15 & -0.15 & -0.17 & -0.16 & -0.17 & -0.14 & -0.10 & -0.06 & -0.14 & -0.14 & -0.11 \\
\hline TALLAND TC-S & 0.07 & 0.08 & 0.09 & 0.16 & 0.14 & 0.17 & 0.12 & 0.14 & 0.06 & 0.04 & 0.14 & 0.16 & 0.11 \\
\hline TALLAND FA-S & -0.10 & -0.09 & -0.11 & -0.16 & -0.12 & -0.16 & -0.10 & -0.14 & -0.10 & -0.06 & -0.11 & -0.16 & -0.14 \\
\hline TALLAND EO-B & -0.12 & -0.11 & -0.08 & -0.12 & -0.12 & -0.09 & -0.07 & -0.09 & -0.13 & -0.09 & -0.13 & -0.13 & -0.09 \\
\hline TALLAND FA-B & -0.05 & -0.03 & -0.12 & -0.13 & -0.10 & -0.13 & -0.13 & -0.12 & -0.04 & -0.01 & -0.10 & -0.13 & -0.11 \\
\hline TALLAND TL-S & 0.02 & 0.03 & 0.10 & 0.09 & 0.13 & 0.14 & 0.12 & 0.08 & 0.01 & 0.02 & 0.12 & 0.10 & 0.06 \\
\hline TALLAND TC-C & -0.01 & 0.05 & 0.06 & 0.13 & 0.10 & 0.15 & 0.11 & 0.12 & 0.02 & 0.04 & 0.09 & 0.11 & 0.02 \\
\hline TALLAND TL-B & 0.02 & 0.02 & 0.08 & 0.10 & 0.13 & 0.13 & 0.13 & 0.11 & 0.01 & 0.03 & 0.10 & 0.08 & 0.04 \\
\hline TALLAND TL-C & -0.02 & 0.03 & 0.08 & 0.12 & 0.11 & 0.14 & 0.12 & 0.12 & 0.00 & 0.02 & 0.09 & 0.10 & 0.02 \\
\hline TALLAND EO-S & -0.10 & -0.06 & -0.02 & -0.07 & -0.04 & -0.01 & -0.03 & -0.04 & -0.10 & -0.02 & -0.09 & -0.05 & -0.10 \\
\hline TALLAND EO-C & -0.03 & -0.03 & 0.00 & -0.01 & -0.04 & -0.02 & 0.00 & 0.02 & -0.04 & -0.02 & -0.07 & -0.02 & -0.04 \\
\hline MAZE NTFS-L & -0.10 & -0.11 & -0.12 & -0.06 & -0.20 & -0.14 & -0.14 & -0.08 & -0.14 & -0.08 & -0.17 & -0.10 & -0.06 \\
\hline MAZE TE-L & -0.06 & -0.11 & -0.11 & -0.07 & -0.16 & -0.13 & -0.13 & -0.11 & -0.10 & -0.09 & -0.15 & -0.10 & -0.05 \\
\hline MAZE NTC-L & -0.07 & -0.09 & -0.11 & -0.03 & -0.15 & -0.09 & -0.10 & -0.07 & -0.11 & -0.07 & -0.13 & -0.07 & -0.04 \\
\hline MAZE NTC-S & -0.12 & -0.07 & -0.08 & -0.04 & -0.11 & -0.09 & -0.07 & -0.06 & -0.12 & -0.08 & -0.11 & -0.09 & -0.09 \\
\hline MAZE TT-L. & -0.04 & -0.06 & -0.09 & -0.04 & -0.14 & -0.07 & -0.10 & -0.06 & -0.06 & -0.04 & -0.13 & -0.06 & -0.01 \\
\hline MAZE NTFS-S & -0.11 & -0.07 & -0.05 & -0.03 & -0.10 & -0.07 & -0.06 & -0.05 & -0.11 & -0.06 & -0.04 & -0.10 & -0.06 \\
\hline MAZE TE-S & -0.09 & -0.04 & -0.06 & -0.04 & -0.10 & -0.09 & -0.07 & -0.05 & -0.08 & -0.02 & -0.07 & -0.09 & -0.06 \\
\hline MAZE Repro-L & -0.07 & -0.05 & -0.06 & -0.04 & -0.05 & -0.01 & -0.06 & -0.04 & -0.11 & 0.00 & -0.09 & -0.04 & -0.08 \\
\hline MAZE TT-S & -0.05 & -0.01 & -0.03 & -0.02 & -0.06 & -0.04 & -0.04 & -0.02 & -0.04 & 0.00 & -0.07 & -0.05 & -0.03 \\
\hline MAZE TTLTT-L & 0.04 & 0.04 & 0.03 & -0.02 & 0.03 & 0.03 & 0.00 & 0.04 & 0.05 & 0.08 & -0.01 & 0.00 & 0.03 \\
\hline MAZE TST-L & 0.04 & 0.04 & -0.01 & 0.03 & -0.02 & 0.03 & 0.01 & 0.01 & 0.05 & -0.01 & 0.00 & 0.03 & 0.03 \\
\hline MAZE Repro-S & -0.01 & 0.01 & -0.01 & 0.00 & -0.02 & 0.00 & -0.03 & 0.00 & 0.02 & 0.02 & -0.10 & 0.00 & -0.02 \\
\hline SEASHORE Errors-B & -0.10 & -0.08 & -0.13 & -0.09 & -0.13 & -0.13 & -0.13 & -0.09 & -0.10 & -0.08 & -0.13 & -0.13 & -0.08 \\
\hline SEASHORE ErTOrS-A & 0.02 & 0.00 & -0.05 & -0.08 & -0.14 & -0.15 & -0.13 & -0.09 & 0.01 & 0.00 & 0.01 & -0.05 & 0.00 \\
\hline SEASHORE Errors-C & 0.01 & -0.03 & -0.05 & -0.04 & -0.05 & -0.08 & -0.04 & -0.04 & -0.02 & -0.01 & -0.07 & -0.04 & 0.00 \\
\hline SEASHORE Blanks & -0.03 & -0.06 & -0.01 & -0.03 & -0.01 & 0.01 & 0.01 & -0.04 & -0.06 & -0.05 & -0.05 & -0.02 & -0.02 \\
\hline WISCONSIN TCat & 0.04 & 0.04 & 0.14 & 0.07 & 0.12 & 0.07 & 0.14 & 0.07 & 0.05 & 0.02 & 0.14 & 0.06 & 0.06 \\
\hline WISCONSIN Other & -0.03 & -0.05 & -0.09 & -0.08 & -0.10 & -0.05 & -0.09 & -0.07 & -0.05 & -0.04 & -0.07 & -0.03 & -0.04 \\
\hline WISCONSIN TErr & -0.03 & -0.04 & -0.11 & -0.06 & -0.12 & -0.07 & -0.14 & -0.06 & -0.04 & -0.03 & -0.14 & -0.05 & -0.03 \\
\hline WISCONSIN TCOIT & 0.01 & 0.01 & 0.07 & 0.05 & 0.10 & 0.07 & 0.12 & 0.05 & 0.02 & 0.00 & 0.09 & 0.06 & 0.03 \\
\hline WISCONSIN NTFS & -0.03 & -0.01 & -0.02 & -0.01 & -0.01 & 0.01 & 0.00 & 0.00 & -0.06 & 0.01 & -0.03 & 0.01 & -0.01 \\
\hline WISCONSIN TSetFails & -0.04 & -0.01 & -0.08 & -0.03 & -0.04 & 0.03 & -0.02 & 0.01 & -0.03 & 0.00 & -0.02 & 0.00 & -0.03 \\
\hline DIGITS DB & 0.02 & 0.06 & 0.11 & 0.05 & 0.09 & 0.08 & 0.10 & 0.08 & 0.04 & 0.05 & 0.11 & 0.05 & 0.04 \\
\hline DIGITS SS & -0.01 & 0.04 & 0.09 & 0.04 & 0.09 & 0.08 & 0.09 & 0.07 & 0.02 & 0.04 & 0.07 & 0.04 & 0.02 \\
\hline DIGITS DF & -0.02 & 0.02 & 0.04 & 0.03 & 0.06 & 0.07 & 0.05 & 0.05 & 0.02 & 0.02 & 0.03 & 0.03 & -0.02 \\
\hline
\end{tabular}

Note: Alcohol scores were nonlinearly transformed as in refs. 41 and 42 . Sample sizes range from 442 to 462 . See Table 2 for decoding acronyms. Order of tests and scores is in accordance with salience for alcohol (see Table 4).

where $r_{i j}$ is the correlation of Alcohol item $i$ and Attention/ Memory item $j$, the $(i, j)$ element of the matrix $R_{A B}$ of correlations given in Table 3. (Note that covariance, "cov," was substituted for correlation, "corr," in Eq. 3, because all the $A_{i}$ are scaled to have variance 1.) These $13 \alpha$ 's are the saliences of the 13 Alcohol scores for the Attention/ Memory LV.
The weights $\beta_{\mathrm{j}}$ of the performance variables are computed similarly, by requiring

$$
\beta_{\mathrm{j}} \propto \sum_{\mathrm{i}=1}^{13} \alpha_{\mathrm{i}} \mathrm{r}_{\mathrm{ij}} \text { for each } \mathrm{j} .
$$

The $52 \beta$ 's, one/performance variable, are the saliences of the outcomes for prediction by the Alcohol LV. (These 
$\beta$ 's are not the familiar " $\beta$ weights" of multiple regression.) For convenience, we scale the weights so that $\sum \alpha_{i}^{2}=\sum \beta_{j}^{2}$ $=1$. See refs. 41 and 50 for details of computation of the $\alpha$ 's and $\beta$ 's. They may be derived from the singular-value decomposition of the matrix $R_{A B}$, or in several other equivalent ways. One approach to estimating these coefficients is to cycle between Eqs. 3 and 4, computing the $\alpha$ 's from Eq. 3 given the $\beta$ 's, then new $\beta$ 's from Eq. 4 , etc.

We extend this computation slightly, as described in ref. 41 , to allow empirical nonlinear transformations of the Alcohol variables only, as follows. After the computed $\beta$ 's are used as coefficients of a preliminary estimated Attention/Memory LV (Eq. 2), each Alcohol item is rescaled nonlinearly but monotonically so that its prediction of this tentative outcome LV is most nearly linear. This is accomplished using a scatterplot smoother. ${ }^{51}$ These transforms replace the original alcohol items and the whole cycle of Eqs. 3 and 4 is repeated until convergence. The resulting transformed alcohol variables are virtually identical to those displayed in our previous reports, and are not shown herein. [Note that the mothers with the two highest alcohol scores (one who had the highest AAD score and one who had the highest AAP score) have been recoded to the next highest scores on these two values to reduce their influence. As a result, the two children with FAS in the sample (one born to each of these mothers) do not have undue influence over these correlations.]

Finally, LV scores are computed using the saliences as coefficients in linear combinations of the 13 Alcohol scores and 52 performance scores, respectively, as in Eqs. 1 and 2.

In this methodology, permutation analyses provide information on the uncertainty of the findings, and thus replace traditional significance testing. ${ }^{41}$ Because this study is not concerned with testing the significance of these individual coefficients (except for that of the Alcohol LV itself), they are not described herein. The relationship of PLS to other psychometric approaches has been extensively investigated. References to this literature can be found in refs. 21 and 46.

\section{Covariate Selection}

In assessing possible causal associations between prenatal alcohol exposure and later neuropsychologic functioning of the child, it is important to consider whether observed relationships involving alcohol can be attributable to confounding with other factors. We use multiple regression techniques to evaluate the impact of important covariates on the Alcohol/Attention-Memory relationships detected in the PLS analyses. Beginning with the prenatal interview and continuing at each postnatal assessment, we recorded as many potentially confounding and/or intervening variables as possible. A list of $\sim 150$ such covariates and the rationale for their selection has been published previously. ${ }^{23}$ This list includes three types of measures: demographic variables that might directly affect the outcome measures; other exposure variables that are sometimes correlated with alcohol use and that could, if ignored, be responsible for spurious relationships with alcohol exposure; and selected postnatal factors that predict behavior and so may serve as intervening variables between alcohol exposure and outcome.

In multiple regressions, we adjusted the correlation between the alcohol and outcome LVs to take covariates into account. Covariates described in "Methods" and "Results" were selected for the multiple regression analysis if they were substantially (usually "significantly") correlated with some of the outcome measures and/or alcohol measures, or if the literature suggested possible effects on the fetus. The only covariates that might bias our estimates of alcohol-outcome relationships are those substantially correlated with both alcohol exposure and outcome. But we also considered variables that are predictive of the outcomes but are not related to alcohol exposure. These might reduce the "noise" in assessment of the attention/memory outcomes and enable more precise estimates of alcoholoutcome effects. We use these multiple regressions only to "challenge" the causal interpretation of the LV-LV correlation; we do not recommend that any of the other fitted coefficients be interpreted.

\section{RESULTS}

A single two-block PLS analysis of the $13 \times 52$ matrix of correlations in Table 3 results in the analysis of Table 4 and the scatterplot of scores to the left in Fig. 2. It is appropriate to judge these analyses by a regression-like statistic, ${ }^{41,50}$ the percentage of summed squared correlation explained by the first pair of latent variables. If the PLS analysis is "perfect," every row of the matrix in Table 3 would be proportional to the left column in Table 4, and every column in Table 3 would be proportional to the right column in Table 4. The statistic we compute measures the goodness-of-fit with which the two columns of Table 4 together account for all the entries of Table 3. For these 13 alcohol scores and 52 outcomes, that value is $90 \%$, indicating that most of the whole table of correlations between alcohol and outcome can be accounted for in terms of this single pair of latent variables. When such a large percentage of the full table of correlations between alcohol and outcome is described in the first LV, it is not necessary to examine the data for a second LV pair, as we did in a previous analysis of data through 7 years. ${ }^{21,50}$

Next we inspect Table 4 to ascertain which Alcohol scores and which Attention/Memory scores are more salient for the facing LV. The comparisons make sense only separately, column by column; it is inappropriate to compare $\alpha$ 's to $\beta$ 's after the standardization here. Considering the saliences (correlations with the Attention/Memory LV) of the items in the Alcohol LV, the entries in the left column only, ADOCC pre and during emerge as most salient for predicting Attention/Memory deficits, although 
Table 4. Saliences for the 2-Block PLS Analysis: 13 Alcohol Scores and 52 Attention/Memory Scores

\begin{tabular}{|c|c|c|c|}
\hline Alcohol LV & $\alpha$ & Attention/Memory LV & $\beta$ \\
\hline \multicolumn{4}{|c|}{ CPT } \\
\hline AA pre & -0.18 & SDRT-X & 0.27 \\
\hline \multirow[t]{2}{*}{ AA during } & -0.22 & SDRT-AX & 0.20 \\
\hline & & SDRT-DX & 0.20 \\
\hline MOCC pre & -0.22 & False Alarms-AX & 0.19 \\
\hline MOCC during & -0.17 & $\begin{array}{l}\text { Ratio False Alarms/Total Presses- } \\
\text { AX }\end{array}$ & 0.16 \\
\hline QFV pre & -0.33 & Mean Peaction Times-DX & 0.12 \\
\hline \multirow[t]{3}{*}{ QFV during } & -0.30 & Mean Reaction Times $-x$ & 0.12 \\
\hline & & False Alarms-DX & 0.10 \\
\hline & & Errors of Omission-AX & 0.10 \\
\hline ADOCC pre & -0.38 & Ratio False Alarms/Total Presses- & 0.09 \\
\hline \multirow[t]{3}{*}{ ADOCC during } & -0.36 & $\mathrm{DX}$ & \\
\hline & & False Alarms- $x$ & 0.09 \\
\hline & & Errors of Omission- $X$ & 0.06 \\
\hline MAX pre & -0.33 & Mean Reaction Times-AX & 0.05 \\
\hline MAX during & -0.28 & $\begin{array}{l}\text { Ratio False Alarms/Total Presses-- } \\
\text { AX }\end{array}$ & 0.04 \\
\hline \multirow[t]{2}{*}{ BINGE pre } & -0.27 & Errors of Omission-DX & -0.03 \\
\hline & & TALLAND & \\
\hline BINGE during & -0.27 & $\begin{array}{l}\text { Total Correct-Both Capitals and } \\
\text { Spaces }\end{array}$ & -0.25 \\
\hline \multirow[t]{9}{*}{ ORDEXC } & -0.20 & False Alarms-Capitals & 0.23 \\
\hline & & Total Correct-Spaces & -0.21 \\
\hline & & False Alarms-Spaces & 0.21 \\
\hline & & Errors of Omission-Both & 0.18 \\
\hline & & False Alarms-Both & 0.17 \\
\hline & & Total Letters-Spaces & -0.15 \\
\hline & & Total Correct-Capitals & -0.15 \\
\hline & & Total Letters-Both & -0.15 \\
\hline & & Total Letters-Capitals & -0.14 \\
\hline \multirow{31}{*}{\multicolumn{2}{|c|}{$\begin{array}{l}\text { Fraction of summed } \\
\text { squared correlation } \\
\text { explained: } 90 \%\end{array}$}} & Errors of Omission-Spaces & 0.09 \\
\hline & & Errors of Omission-Capitals & 0.04 \\
\hline & & STEPPING STONE MAZE & \\
\hline & & No. of Trials to First Success-Long & 0.21 \\
\hline & & Total Errors-Long & 0.19 \\
\hline & & No. of Trials to Criterion-Long & 0.16 \\
\hline & & No. of Trials to Criterion-Short & 0.15 \\
\hline & & Total Time-Long & 0.13 \\
\hline & & $\begin{array}{l}\text { No. of Trials to First Success- } \\
\text { Short }\end{array}$ & 0.12 \\
\hline & & Total Errors-Short & 0.12 \\
\hline & & Reproduction-Long & 0.09 \\
\hline & & Total Time-Short & 0.07 \\
\hline & & Total Time Last 3 Trials-Long & -0.04 \\
\hline & & Total Successful Trials-Long & -0.03 \\
\hline & & Reproduction-Short & 0.02 \\
\hline & & SEASHORE & \\
\hline & & Errors-Trial B & 0.19 \\
\hline & & Errors-Trial A & 0.10 \\
\hline & & Errors-Trial C & 0.07 \\
\hline & & No. of Trials Left Blank & 0.04 \\
\hline & & WISCONSIN & \\
\hline & & Total Categories & -0.15 \\
\hline & & Other Responses (no.) & 0.13 \\
\hline & & Total Errors & 0.13 \\
\hline & & Total Correct & -0.10 \\
\hline & & $\begin{array}{l}\text { No. of Trials First Successful Cate- } \\
\text { gory }\end{array}$ & 0.06 \\
\hline & & Total Failures to Maintain Set & 0.03 \\
\hline & & DIGIT SPAN & \\
\hline & & Digits Backward & -0.12 \\
\hline & & Digit Span Scaled Score & -0.10 \\
\hline & & Digits Forward & -0.06 \\
\hline
\end{tabular}

Note: Analysis pertains to the correlations in Table 3. All alcohol scores except BINGE were optimally nonlinearly transformed as noted in the text. Sum of squares of each column is 1.00 . Numbers in the same column can be compared. Alcohol saliences are proportional to the correlations of the alcohol measures with the Attention/Memory LV score. Outcome saliences are proportional to the correlation of the items with the prenatal Alcohol LV score. A negative salience under $\beta$ indicates an inverse relation with alcohol. the two QFV scores and the two MAX scores also have substantial predictive power.

Likewise, for the Attention/Memory items, we examine the entire column of 52 saliences for Alcohol. Although in the table these are grouped by the tests from which they derive to facilitate visual scanning, in the two-block analyses they have been analyzed as 52 separate items. According to the right-hand column in Table 4, several scores from the CPT, TALLAND, and MAZE have higher saliences than those from the other tests administered. These tests thus may be considered generally more sensitive to prenatal alcohol effects in 14-year-old offspring than the other three tests (SEASHORE, WISCONSIN, and DIGITS), which collectively produced only one salience in the top third of the 52. In this method of analysis, there is no formal statistical attempt to determine whether one or another of these scores is "significant" in relation to its peers-such tests would be difficult to construct and interpret in view of the number of multiple comparisons involved. The scores within each LV are compared only to their peers in assessing the strength of their salience for the other LV - there is no "meaning" in the comparison of the size of the saliences for individual scores across LVs.

1. The Alcohol LV. Alcohol LV saliences are tabulated in the column of $\alpha$ 's, Table 4; the binge scores (ADOCC, QFV, MAX, and BINGE) have the highest salience. The MOCC and AA scores are the least salient for this 14-year Attention/Memory LV. The "prepregnancy recognition" scores are more salient than the "during pregnancy" scores, but less distinctly so than in our analysis of 7-year neurobehavioral outcomes. ${ }^{41,42}$ In the present analyses, the pattern of drinking is more salient for attention/memory performance than is the timing of drinking; and at both time periods, the number of drinks/occasion is more salient for attention/memory performance than is the number of drinking occasions.

2. The Attention/Memory LV. The saliences of the individual attention/memory scores for the Alcohol LV are tabulated in the column of $\beta$ 's in Table 4 . The tests with the highest general saliences for alcohol are CPT Vigilance, TALLAND Letter Cancellation, and the Stepping Stone MAZE. For the CPT, the score with the highest salience for alcohol is the Standard Deviation of Reaction Time (SDRT) for all three CPT tasks (X, AX, and DX). Two additional scores from the AX task are also salient for alcohol: False Alarms and Ratio of False Alarms to Total Presses. These findings indicate that the more alcohol exposure, the more likely were the subjects to have a highly variable response rate and to fail to withhold a response on the task requiring them to press only to an $\mathrm{X}$ preceded by an A.

On the TALLAND Letter Cancellation Test, the scores most salient for alcohol are Total Correct, Both Capitals and Spaces (which is the last and hardest task), and False Alarms (crossing out items that should not have been crossed out) on all three tasks. As with the CPT, False 

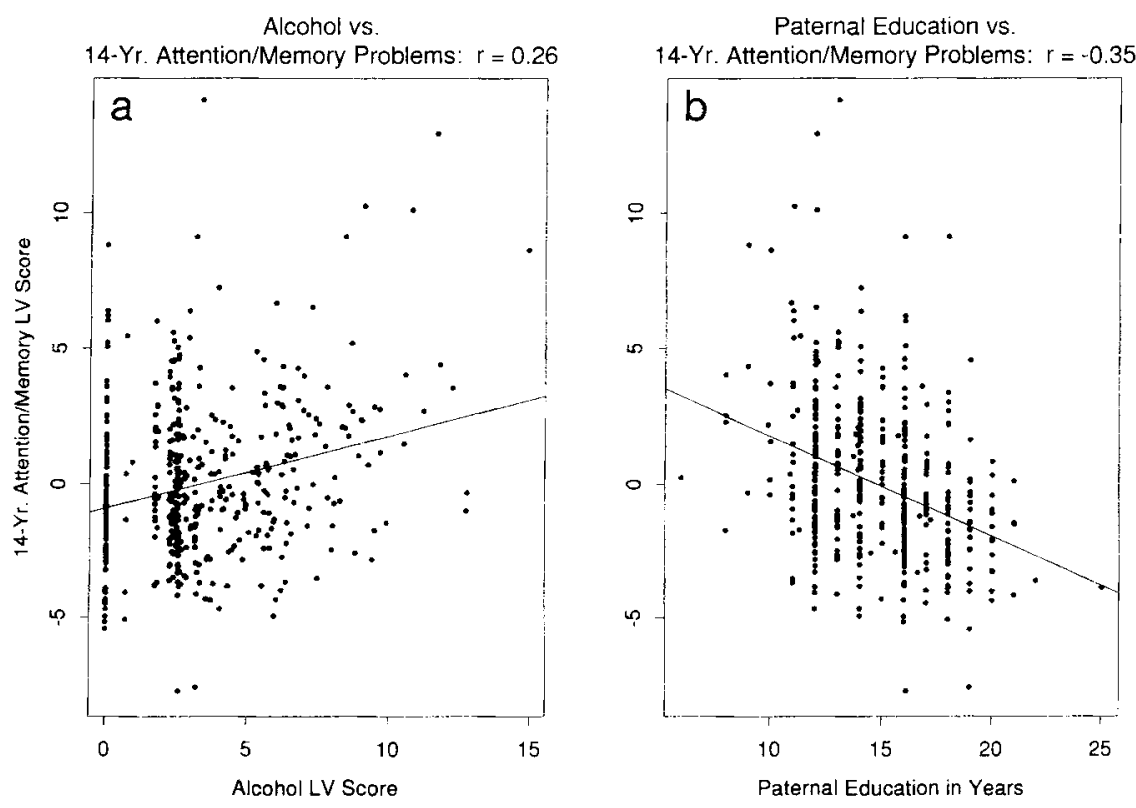

Fig. 2. Two principal determinants of the 14-year Attention/ Memory LV. (Left) Prediction by the Alcohol LV of this study. (Right) Prediction by paternal education. Problems with Attention/Memory performance are increased with increasing use of alcohol pre- and during pregnancy and decreased with increasing paternal (or maternal) years of education. Straight lines indicate the corresponding simple regressions. In the left panel, the "vertical line" at the far left of the Alcohol scale corresponds to abstainers. The next "stripe" combines various patterns of low-dose drinking (pre or during periods) with comparable contributions to the LV score. Two outlying patterns of dose have been somewhat truncated at the right (see text).
Alarms on the TALLAND Letter Cancellation task were in general more salient for alcohol than were Omission Errors. On the MAZE, the scores most salient for alcohol were the Number of Trials to First Success and Total Errors.

The SEASHORE Rhythm Test is moderately salient for alcohol, but not as salient as it was at the 7-year exam. ${ }^{42}$ The WISCONSIN Card Sort is moderately salient for alcohol, primarily the Total Number of Categories and the "Other Response" score, which reflects the number of extraneous noncategory responses. WISC-R DIGIT SPAN was only modestly salient for alcohol, whereas at the 7 year exam it was one of the three strongest subtests of the WISC-R in terms of alcohol salience.

This Attention/Memory LV should not be thought of as a "factor" explaining the intercorrelations of these 52 scores in our population or in a normative sample. It is computed to summarize not the implications of these scores among themselves, but instead the manner in which they are simultaneously shifted owing to the effects of alcohol. The 52 variables intentionally tapped a very wide range of underlying aspects of attention and memory performance; within the confines of a 4-hr test battery, it is not possible to measure them all with equivalent reliability. The goal of PLS is to supply simultaneously a profile of saliences for alcohol and a set of paired LV scores, for dose and response, that have the largest covariance. What we are optimizing, then, is the understanding of the effects of alcohol, not of the structure of such complex constructs as memory and attention per se. We have made this point in earlier publications as well (e.g., refs. 17 and 21).

3. Scores and Covariates. In the last step of a PLS analysis, LV scores are computed using the saliences as coefficients in linear combinations of the 13 Alcohol scores and 52 performance scores, respectively, as in Eqs. 1 and 2. Figure 2a displays a scatterplot of the Alcohol
LV scores against the Attention/Memory LV scores for the 462 subjects. The trend in the scatterplot is welldescribed by the regression line drawn on the figure. The correlation coefficient is 0.26 , which is highly significant. Reference 21 deals in great detail with the underlying structure of this single LV score, in particular with the variety of actual drinking behaviors represented by a single "profile."

Further analyses of this pair of LV scores were conducted using multiple regression techniques as described in "PLS Statistical Analysis" to guard against attributing to alcohol effects that really pertain to some correlated variable. The strongest of the other predictors of the 14year Attention/Memory LV are measures of SES, such as paternal education $(r=-0.35)$ and race (an indicator for Blacks, $r=0.24$ ). The Alcohol LV correlates more strongly with the 14-year Attention/Memory LV $(r=0.26)$ than do any of the other drugs assessed (e.g., marijuana, $r=$ 0.18 ; nicotine, $r=0.15$ ). When these demographic covariates are partialled out, the alcohol effects remain highly significant, $r=0.18$. Further adjustment for other covariates and exposures does not substantially reduce this estimated alcohol effect. Some aspects of the postnatal environment, such as breastfeeding, number of adults in household, birth order, and mother-infant interaction scores, are also correlated with the Attention/Memory LV, but likewise do not substantially change the adjusted effect of the Alcohol LV once paternal education and race are in the model. We conclude that the effects of alcohol reported are not likely to be attributable to other associated causes. (Assuming a high correlation between pre- and postnatal drinking, the postnatal dose cannot be partialled out in this way. We note, however, that this same Alcohol LV also shows strong effects on the neonatal outcome measures, ${ }^{21}$ for which there can be, of course, no "effect" of postnatal drinking.) Figure 2 compares the dependence 
of the 14-year Attention/Memory LV on paternal education with its dependence on this Alcohol LV.

4. A Simple Longitudinal Path Model. (Fig. 3) shows the relationship of the 14-year Attention/Memory LV to earlier neurobehavioral functioning. For 460 of the 462 subjects seen at 14 years, we had neurobehavioral data obtained at some earlier wave of observation, from birth through 7 years. We use this earlier data to evaluate what proportion of the correlation observed at 14 years between prenatal alcohol and the attention-memory LV may be explained in terms of deficits demonstrated by 7 years of age. In a previous report, ${ }^{21}$ we introduced a $0-7$ Outcome LV summarizing the effects of prenatal alcohol on 474 outcomes measured at 1 or 2 days, 8 or 18 months, and 4 or 7 years. This incorporated measures of attention, mentation, and neurobehavioral function at all ages, and measures of learning disabilities at age 7 . This massively redundant LV score is correlated 0.27 with the present Alcohol LV and a full 0.67 with the 14-year Attention/Memory LV examined herein.

As we noted in Fig. 2a, the Alcohol LV calculated in this study is correlated 0.26 with the 14-year Attention/ Memory LV. This same Alcohol LV correlates as well ( $r$ $=0.27$ ) with the full composite $0-7 \mathrm{LV}$ from the longitudinal analysis. Figure 3 presents a path model for the simple decomposition of the correlation we observe now (0.26) into an indirect effect in terms of the deficits observed from birth to 7 years $(0.18)$ and the presumably "new" or "direct" effect of prenatal alcohol that is not attributable to those effects measured by age 7 years $(0.08)$. Most (0.18) of the prenatal alcohol effect on 14-year Attention/Memory was already demonstrated in outcomes measured by 7 years of age; only 0.08 is a "new" or direct effect after age 7 years. Thus, the 14-year Attention/Memory findings are seen as enduring effects of prenatal alcohol on offspring performance: first measured in the first 7 years of life and now again at 14 years.

\section{DISCUSSION}

This study represents the first systematic investigation of the long-term consequences of alcohol neuroteratoge-

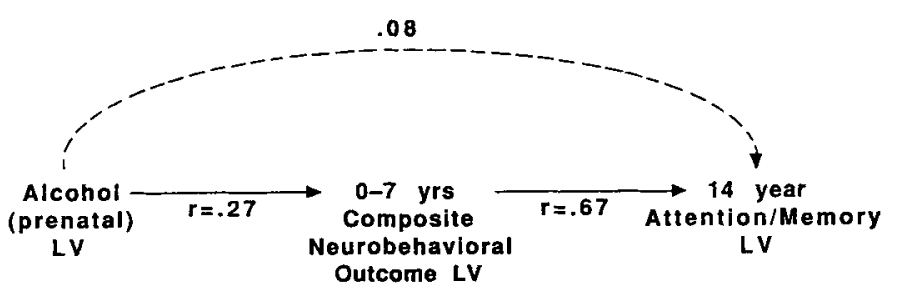

Fig. 3. Direct and indirect paths for the effect of prenatal alcohol on the 14year Attention/Memory LV. A simple causal chain model decomposes the AlcoholAttention/Memory LV correlation into the sum of an "indirect effect" via the previously measured deficits and a "direct effect" representing deficits not predicted by those previously measured. With obvious notation this decomposition is Cor(Alc LV , AM LV $)=$ Cor(Alc, 0-7 LV) $\times$ Cor(0-7 LV, AM LV) + "direct effect," where the direct effect is computed by subtraction. This calculation corresponds to one of the "normal equations" solved in computing a multiple regression of the Attention/ Memory LV on the 0-7 year outcome LV and Alcohol. nesis in humans. The study's design features derive from the principles of behavioral teratology, ${ }^{20}$ modified as necessary for human studies in which dose is not under the control of the investigator. To compensate for uncertainty in the correct titration of dose and for errors of selfreported dose, we assess dose highly redundantly using 13 overlapping measures of drinking. ${ }^{50}$ Attention/Memory performance was targeted as an outcome domain because of its theoretical, experimental, and clinical relevance. Within this domain, 52 test scores from six attention/ short-term memory tests were evaluated relative to their salience for alcohol.

We find that prenatal alcohol exposure continues to affect the neurobehavioral functioning of young adolescents as it did in laboratory assessments at 4 years ${ }^{13,52,53}$ and 7 years ${ }^{15,41,42,54}$ and in an assessment of classroom behavior at 11 years. ${ }^{17}$ Our Attention/Memory Battery, carefully selected from the experimental and clinical literature, was sensitive to prenatal alcohol effects 14 years after exposure. Socioeconomic factors, nutrition, other drug exposures, and a variety of potentially traumatic environmental events do not account for the results reported herein. The PLS statistical method adequately accommodated the complex multivariate data and detected the unidimensionality of the underlying pattern of relationship between "dose" and "response." In this section, we discuss the findings from this population-based study, along with specific findings from the clinical and experimental literature, to develop an integrated approach to the understanding of the subtle prenatal brain damage induced by exposure to alcohol.

\section{Some Components of Attention/Memory Function Relate More Strongly Than Others to Prenatal Alcohol Exposure}

Figure 4 presents scatters on four of the outcomes most salient for alcohol. In general, tasks requiring more complex decision-making were the most sensitive in detecting the long-term effects of prenatal alcohol exposure. Thus, False Alarms on the simple " $X$ " task were not sensitive to prenatal alcohol effects at 14 years, although they had been at earlier ages. ${ }^{13,15}$ The task that produced the most alcohol-related False Alarms was the more difficult AX task of the CPT, which requires that the subject withhold a response to the letter " $X$ " unless it was preceded by an "A." False Alarms on the AX task of the CPT have been reported to be increased in hyperactive children, ${ }^{55}$ as well as in learning-disabled, nonhyperactive children, up through age $14-15$ years. ${ }^{56}$ Similarly, it was the "Both" score of the TALLAND Letter Cancellation Test that was most sensitive to alcohol-related performance deficits; in this test, the subject must work on two tasks simultaneously - crossing out all capital letters and all spaces.

The Stepping Stone MAZE, another difficult task, was likewise effective in detecting alcohol effects. In this test, the correct sequence of turns cannot be discovered by 


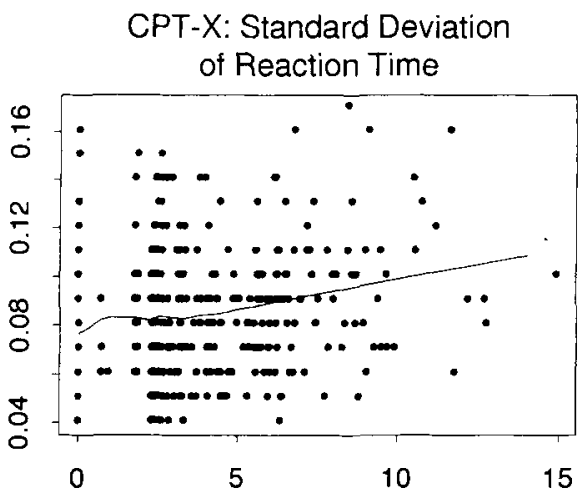

TALLAND: False Alarms - Capitals

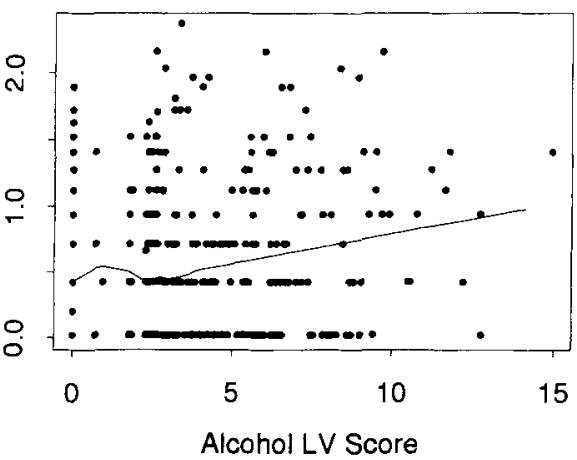

TALLAND: Total Correct - both Capitals and Spaces

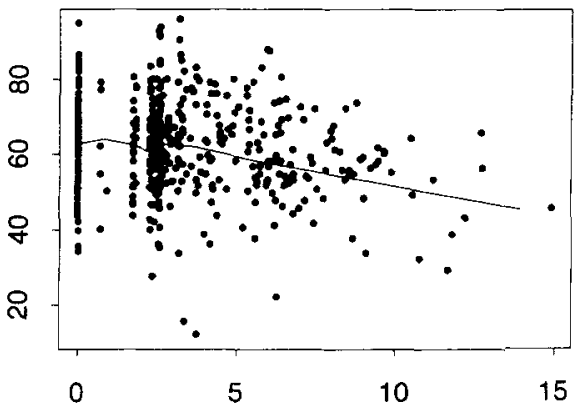

STEPPING STONE MAZE: \# of Trials to 1st Success - Long Maze

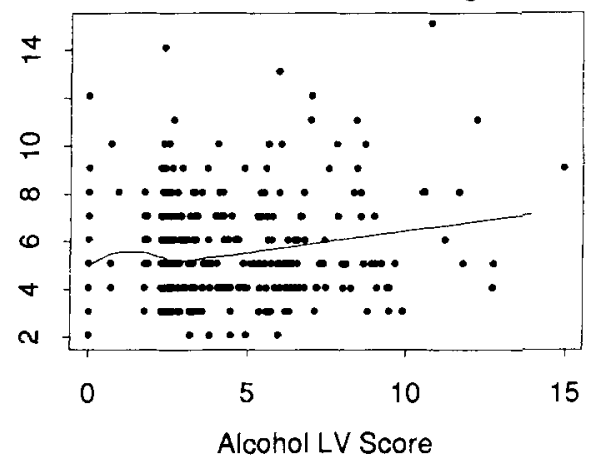

Fig. 4. Scatters of four of our most salient outcome tasks plotted against the Alcohol LV. Lines on the plot represent expected responses for each value of the latent alcohol dose. They were produced by "supsmu," a scatterplot smoother in S-PLUS. ${ }^{49}$ inspection, but only by trial and error and by integrating feedback. Successful performance depends on remembering the experience of previous trials, namely a whole sequence of interrelated turns in the hidden path-a much more demanding task than the simple memory requirements of the Digit Span task. Milner believes the Stepping Stone MAZE is sensitive to memory disorders in general and not merely to disorders of spatial perception. ${ }^{57} \mathrm{~Pa}$ tients with hippocampal lesions showed the most severe deficits on her noncomputerized version of this test. ${ }^{58}$ The Stepping Stone MAZE is similar to the spatial learning task of the Morris Water Maze ${ }^{44}$ and the 12-arm radial maze ${ }^{6}$ on which rats prenatally exposed to alcohol perform poorly even as adults. Goodlett ${ }^{6}$ describes alcohol-exposed rats (receiving only two binge doses) in the 12-arm radial maze as making classic hippocampal errors on this task. These errors include repeatedly entering unbaited arms within a given session, and repeatedly entering baited arms once the bait was gone. These errors are similar to the repetitive errors and high rates of broken rules reported by Milner in her patients with hippocampal, frontal, and right parieto-temporo-occipital lesions. These converging findings suggest that the Stepping Stone MAZE, which we used previously to document memory deficits in adults with $\mathrm{FAS}^{43}$ and which has been one of the tests most salient for prenatal alcohol effects, deserves further study as an outcome for studies of alcohol teratogenesis in humans.

The strong salience of the CPT SDRT scores for prenatal alcohol is also of considerable interest. Measures of individual variability in response time have long intrigued neuropsychologists studying the long-term sequelae of traumatic brain injury (e.g., ref. 59). More recently, Stuss et al. ${ }^{60}$ have reported differences in SDRT in a wide variety of traumatic brain injury patients (compared with matched normal controls), including many who were well into recovery (approximately 1 year posttrauma) and many who had suffered only concussions without focal lesions. These neuropsychologists suggest that inconsistencies in response speed and performance are biologically related to brain dysfunction. Earlier studies reported increased reaction time variability in children with hyperactivity ${ }^{61}$ and "minimal brain damage." ${ }^{62}$ SDRT and False Alarms on the CPT AX task have also been associated with normal aging. They are hypothesized to represent microlapses of attention. ${ }^{35,36}$ Our findings may be relevant to the experimental research of Phillips and colleagues, who have documented developmental alcoholinduced delays in glial cell formation and alterations in myelin acquisition. ${ }^{5,63,64}$ These authors have proposed that permanent reduction in myelin thickness could relate to reductions in nerve fiber conduction rates, thereby altering the communication between various parts of the CNS. The present study contributes to this work by documenting alcohol-related deficits in spatial memory, attentional processes, and inhibitory difficulties, as well as increased and unpredictable performance variability in human subjects as a function of their prenatal alcohol exposure. 
The components of the NIMH Battery thought to measure the focus and sustain components of attention (the TALLAND and the CPT) were the most strongly related to prenatal alcohol of all the measures in our Attention/ Memory Battery. The weaker findings with respect to the shift and encoding components of attention could be attributable to the specifics of the tests used, namely our computer adaptation of the WISCONSIN, and the very simple type of short-term memory required by DIGIT SPAN. (Data on a smaller sample of adolescents from this cohort did reveal prenatal alcohol effects on a more complex task also thought to tap the encoding component of attention, namely the Arithmetic Subtest of the WISC$\mathrm{R}^{25}$ ) The short-term memory test requiring manipulation of complex information (Stepping Stone Maze) was a more sensitive indicator of prenatal alcohol exposure in 14-year-old subjects than the simple short-term recall required by DIGIT SPAN or the SEASHORE. As these latter two tests were among the most sensitive to prenatal alcohol effects when the subjects were 7 years old, ${ }^{42}$ these findings are congruent with the experimental studies demonstrating that increasingly difficult tasks are needed to detect the long-term effects of early alcohol exposure in older animals. ${ }^{6}$ An alternative explanation is that the underlying salient dimension of these tasks for alcohol effects is complex motor coordination. In the PLS analysis, nonmotor tasks (i.e., DIGIT SPAN and SEASHORE) were the least salient for Alcohol.

In summary, the early adolescent consequences of prenatal alcohol involve response inhibition difficulties in complex problem-solving, poorer learning from experience in short-term recall of complex information, and fluctuating attentional states. The role of motor control in task performance deserves further study.

\section{Some Components of Prenatal Alcohol Exposure Are Stronger Than Others in Their Relationship to the 14- Year Attention/Memory Tests}

Now we turn to the question of dose. Women in this study reported variable alcohol use patterns during pregnancy and before they knew they were pregnant. Alcohol dose, as represented by the self-report measures used in these analyses, can only be viewed as an estimate of actual fetal exposure. Yet, for all its flaws, self-report is virtually the only satisfactory method for estimating alcohol dose, certainly superior to biologic markers ${ }^{65}$ in the richness and diversity of its alternate assessments of dose. Women in the study were interviewed at a time (1974-1975) when there was little general knowledge about the risks associated with drinking during pregnancy, and great care was taken to obtain as valid and reliable self-report as possible. In 1974-1975, the abstainer rate by self-report was stable at $19-20 \%$ for women for the two time periods [prior to pregnancy recognition and during (mid) pregnancy]. In a study conducted 10 years later, after the Surgeon General recommended not drinking during pregnancy or when planning a pregnancy, Day ${ }^{66}$ found (in a low socioeconomic class cohort) that the self-reported abstainer rate was stable at $16 \%$ prior to pregnancy and at 3 years postpartum, but increased to $55 \%$ in midpregnancy (1983-1985 data). Imprecision in the estimation of the independent variable is more likely to contribute to null findings than to the finding of an alcohol effect. Had we been able to measure alcohol dose to the fetus more accurately, our findings would likely be stronger.

In this study of 14-year-olds, as in earlier reports at 7 and 11 years, the prenatal drinking patterns associated with highest risk to the offspring are those in which drinks are clustered (average Drinks/Occasion, Maximum Drinks any Occasion, and 5 or More Drinks any Occasion). ${ }^{17,21,41,42,54}$ This is congruent with the experimental literature that has shown that peak maternal blood alcohol level is a better predictor of offspring effects than administered dose, and that alcohol administered in a condensed fashion is more deleterious than the same alcohol administered sequentially. Offspring effects associated with the binge pattern of exposure in experimental studies have included microencephaly, hyperactivity, and impaired spatial navigation learning. ${ }^{67-72}$ Schenker et al. ${ }^{73}$ in a major review of the pathogenesis of FAS, concluded, "short, high dose concentrations may be especially deleterious." From the present study, one would infer that the most informative single alcohol score for these adolescent outcomes is ADOCC, at both prepregnancy recognition and midpregnancy. As Table 1 indicates, the average drinks/occasion among drinkers was 2.49 for the prepregnancy recognition period and 2.17 for "during" pregnancy drinking. This indicates that the average drinker in this study drank $2 \frac{1 / 2}{2}$ drinks whenever she drank (prior to pregnancy recognition) and 2 drinks/occasion whenever she drank during pregnancy. These women were clearly not drinking on a daily basis, on average, as the averages of drinking occasions/month were 9 and 4.5, respectively. Although the "typical" drinker in this study never reported 5 or more drinks on an occasion, $39 \%$ of the drinkers in our stratified sample reported this pattern prior to pregnancy recognition and $24 \%$ reported this pattern during pregnancy.

It is important to keep in mind that no single alcohol score among the 13 measured is as good a predictor of the long-term attention/memory consequences as is the underlying latent variable for alcohol dose, a combination of all 13 measured scores. This study indicates that many characteristics of dose are important in contributing to the overall impact of prenatal alcohol on adolescent attention/ memory. The dependence of the Attention/Memory LV on the Alcohol LV (Fig. 2) shows no threshold; neither do several of the regressions of this LV on the alcohol indicators separately. It is clear from Fig. 2 that not all exposed offspring are affected and that prenatal alcohol exposure, as reported by these mothers, does not account for all poorly performing offspring. (By the same token, not all 
smokers die of cancer, and some nonsmokers also die of cancer.) But the likelihood of poor performance on attention/memory tasks clearly increases with increased prenatal alcohol exposure. This is what it means to find a dose-response relationship between maternal drinking during pregnancy and offspring attention/memory performance in early adolescence.

\section{Adolescent Findings Reported Herein Are Linked to Earlier Childhood Performance}

Subtle neurobehavioral and attentional deficits have been associated with prenatal alcohol exposure in this cohort between birth and late childhood (c.f. refs. 11, 13, $15,17,21,22,40-42,52-54,74,75)$. The earliest manifestations of attentional-type deficits in this cohort were on measures of habituation to redundant stimuli on the first day of life. ${ }^{11}$ The more alcohol exposure the neonates had sustained during pregnancy, the poorer was their ability to withhold a response to redundant stimuli. Documentation of neonatal attentional deficits prior to any contact with the postnatal environment further supports the contention that these observed attention/memory deficits in later life are neurologically based and of prenatal origin. At 4 and 7 years, prenatal alcohol was associated with slower processing speed. This was detected as slower reaction time on the CPT and other measures, and also as a longer duration to correct errors on a stylus maze task. ${ }^{75}$

Now, in this study of young adolescents, we find that the 14-year attention/memory LV was correlated 0.67 with the LV summarizing the saliences for alcohol of all neurobehavioral and attentional measures obtained between birth and 7 years of age ${ }^{21}$ Behavioral manifestations of these alcohol-related attentional problems were also evident in ratings by classroom teachers when the children were 11 years of age. ${ }^{17}$ The more alcohol exposed the children had been, in utero, the more likely they were to be rated by their classroom teachers as Not Persistent on Tasks, Slow to Settle Down, In Constant Motion, Distractible, Can't Wait Turn, etc., and to get lower scores on national arithmetic and spelling tests. ${ }^{17}$ One aspect of the clinical significance of these findings is that they appear to be detectable not only in the laboratory, but in the classroom as well.

\section{Design Considerations and Alternate Explanations for the Findings}

Several design features of this study are worthy of note. These mothers were interviewed at a time when alcohol use was not generally known to affect offspring adversely. Consequently, a large proportion of women reported drinking during pregnancy, and at sizeable levels, even though hardly any of these women reported alcohol problems. Although it is possible that some mothers minimized their drinking, this would have had the effect of weaken- ing, rather than strengthening, the relationships reported herein.

By studying a basically low-risk group of mothers (primarily married, well-educated women, all in prenatal care by midpregnancy, and with very low rates of other perinatal risk indicators), the effects of their one high-risk behavior, drinking during pregnancy, could be separated out from what in many studies is a high level of "background noise" also associated with adverse developmental outcomes. By stratifying the sample for smoking across alcohol levels in the initial sample selection ${ }^{22}$ (see Fig. 1), it was possible to separate out effectively what otherwise might have been a hopeless confound between drinking and smoking. By using a "redundant" assessment model at the outset, for both predictors and outcomes, it was possible to detect the adverse consequences of certain important drinking patterns (particularly massing of drinks) for which there was no empirical evidence in 1974 when this study began. Likewise, by utilizing whole batteries of neurobehavioral and attentional tests at each age, it has been possible to demonstrate which outcomes, at which ages, bear the primary association with prenatal alcohol exposure.

As a teratologic study demands consideration of competing hypotheses about causes of adverse outcomes, this study has systematically examined a host of prenatal and postnatal environmental factors that could conceivably affect offspring development. The alcohol relationships reported herein are not mitigated by consideration of competing explanations, such as smoking or other drug use during pregnancy, SES factors, etc. The finding (shown in Fig. 2) that the association of alcohol with offspring attention/memory is similar in magnitude to the relationship of paternal (or maternal) education with attention/ memory is of interest, as parental education, in most studies, carries the main measurable relationship to child outcome.

Not all studies have demonstrated a relationship between prenatal alcohol and offspring attention and information processing. One study has a null finding ${ }^{18}$ whereas another reports positive effects for younger children, ${ }^{76}$ but null findings for older children. ${ }^{19,77}$ Among the design features that contribute to discrepancies among studies such as these are the sample count of heavier drinkers, precision of assessment of "dose," confounding of drinking with important covariates, age of testing, type and precision of outcomes measured, testing conditions, and success of following-up the sample. Although no other studies except ours have examined the late childhood and early adolescent outcomes of prenatal alcohol exposure, four separate studies of younger children (in addition to those involving our cohort) have shown prenatal alcohol effects on attention, memory, and/or information processing in infants and young children. ${ }^{12,14,16,78,79}$

This study extends previous findings from the Seattle Study into early adolescence. Attention/short-term mem- 
ory performance at 14 years shows a dose-response relationship to self-reported measures of maternal alcohol use during pregnancy. However, not all exposed offspring were affected. The adolescent findings are well correlated with previously measured neurobehavioral performance during the first 7 years of life. We hypothesize that these attention/memory deficits will underlie additional developmental consequences of prenatal alcohol exposure measurable at later years.

\section{ACKNOWLEDGMENTS}

We gratefully acknowledge the contributions of the following colleagues in the accomplishment of the 14-year evaluation: coinvestigators and consultants Drs. John Baer, Sterling Clarren, Earl B. Hunt, Beth Kerr, Karen Preston, Ruth Little, and Dale Walker; research assistants Bjorn Levidow, Simon Farr, and Jeanne Gray; outreach worker Natasha Grossman; data technicians Patricia Barron and Tracy Smith; and word processing technician Cara C. Ernst. Above all, we acknowledge the loyal participation of the 464 families who have made this study possible over the past 18 years. This paper is dedicated to the memory of Frank A. Seixas, M.D., whose strong advocacy for fetal alcohol research began as early as 1973 .

\section{REFERENCES}

1. Riley EP: The long-term behavioral effects of prenatal alcohol exposure in rats. Alcohol Clin Exp Res 14:670-673, 1990

2. Driscoll CD, Streissguth AP, Riley EP: Prenatal alcohol exposure: Comparability of effects in humans and animal models. Neurotoxicol Teratol 12:231-237, 1990

3. Miller MW: Effects of prenatal exposure to ethanol on cell proliferation and neuronal migration, in Miller MW (ed): Development of the Central Nervous System: Effects of Alcohol and Opiates. New York, Wiley-Liss Inc., 1992, pp 47-69

4. Pentney RJ, Miller MW: Effects of ethanol on neuronal morphogenesis, in Miller MW (ed): Development of the Central Nervous System: Effects of Alcohol and Opiates. New York, Wiley-Liss, 1992, pp 71-107

5. Phillips DE: Effects of alcohol on the development of glial cells and myelin, in Watson RR (ed): Alcohol and Neurobiology: Brain Development and Hormone Regulation. Boca Raton, FL, CRC Press, 1992, pp 83-108

6. Goodlett CR, Bonthius DJ, Wasserman EA, West JR: An animal model of CNS dysfunction associated with fetal alcohol exposure: Behavioral and neuroanatomical correlates, in Gormezano I, Wasserman EA (eds): Learning and Memory: The Behavioral and Biological Substrates. Englewood, NJ, Lawrence Erlbaum, 1992, pp 183-208

7. West JR, Goodlett CR, Bonthius DJ, Pierce, DW: Manipulating peak blood alcohol concentrations in neonatal rats: Review of an animal model for alcohol-related developmental effects. Neurotoxicology 10:347-366, 1989

8. Goodlett CR, West JR: Fetal alcohol effects: Rat model of alcohol exposure during the brain growth spurt, in Zagon IS, Slotkin TA: Maternal Substance Abuse and the Developing Nervous System. San Diego, Academic Press, Inc., 1992, pp 45-75

9. Riley EP, Barron S, Hannigan JH: Response inhibition deficits following prenatal alcohol exposure: A comparison to the effects of hippocampal lesions in rats, in West JR (ed): Alcohol and Brain Development, New York, Oxford University Press, 1986, pp 71-105

10. Barnes DE, Walker DW: Prenatal ethanol exposure permanently reduces the number of pyramidal neurons in rat hippocampus. Dev Brain Res 1:333-340, 1981

11. Streissguth AP, Barr HM, Martin DC: Maternal alcohol use and neonatal habituation assessed with the Brazelton Scale. Child Dev $54: 1109-1118,1983$
12. Jacobson SW, Jacobson JL, Sokol RJ: Prenatal alcohol exposure and infant information processing ability. Child Dev (in press), 1993

13. Streissguth AP, Martin DC, Barr HM, Sandman BM, Kirchner GL, Darby BL: Intrauterine alcohol and nicotine exposure: Attention and reaction time in 4-year-old children. Dev Psychol 20:533-541, 1984

14. Landesman-Dwyer S, Ragozin A, Little R: Behavioral correlates of prenatal alcohol exposure: A four-year follow-up study. Neurobehav Toxicol Teratol 3:187-193, 1981

15. Streissguth AP, Barr HM, Sampson PD, Parrish-Johnson JC, Kirchner GL, Martin DC: Attention, distraction and reaction time at age 7 years and prenatal alcohol exposure. Neurobehav Toxicol Teratol 8:717-725, 1986

16. Brown RT, Coles CD, Smith IE, Platzman KA, Silverstein J, Erickson S, Falek A: Effects of prenatal alcohol exposure at school age: II. Attention and behavior. Neurotoxicol Teratol 13:369-376, 1991

17. Carmichael Olson H, Sampson PD, Barr HM, Streissguth AP, Bookstein FL: Prenatal exposure to alcohol and school problems in late childhood: A longitudinal prospective study. Dev Psychopathol 4:341359,1992

18. Boyd TA, Ernhart CB, Greene TH, Sokol RJ, Martier S: Prenatal alcohol exposure and sustained attention in the preschool years. Neurotoxicol Teratol 13:49-55, 1991

19. Fried PA, Watkinson B, Gray R: A follow-up study of attentional behavior in 6-year-old children exposed prenatally to marihuana, cigarettes, and alcohol. Neurotoxicol Teratol 14:299-311, 1992

20. Riley EP, Vorhees CV: Handbook of Behavioral Teratology. New York, Plenum Press, 1986

21. Streissguth AP, Bookstein FL, Sampson PD, Barr HM: The enduring effects of prenatal alcohol exposure on child development, birth through 7 years: A partial least squares solution. Ann Arbor, MI, University of Michigan Press (in press), 1993

22. Streissguth AP, Martin DC, Martin JC, Barr HM: The Seattle longitudinal prospective study on alcohol and pregnancy. Neurobehav Toxicol Teratol 3:223-233, 1981

23. Streissguth AP, Sampson PD, Barr HM, Clarren SK, Martin DC: Studying alcohol teratogenesis from the perspective of the fetal alcohol syndrome: Methodological and statistical issues, in Wisniewski HM, Snider DA (eds): Mental Retardation: Research, Education, and Technology Transfer, vol 477. New York, New York Academy of Sciences, 1986, pp 63-86

24. Streissguth AP, Giunta CT: Subject recruitment and retention for longitudinal research: Practical considerations for a nonintervention model, in Kilbey MM, Asghar K (eds): Methodological Issues in Epidemiological, Prevention, and Treatment Research on Drug-Exposed Women and Their Children. National Institute on Drug Abuse Monograph No. 117. Rockville, MD: U.S. Department of Health and Human Services, 1992

25. Streissguth AP, Barr HM, Carmichael Olson H, Sampson PD, Bookstein FL, Burgess DM: Drinking during pregnancy decreases Word Attack and Arithmetic scores on standardized tests: Adolescent data from a population-based prospective study. Alcohol Clin Exp Res (in press)

26. Mirsky AF, Anthony BJ, Duncan CC, Ahearn MB, Kellam SG: Analysis of the elements of attention: A neuropsychological approach. Neuropsychol Rev 2:109-145, 1991

27. Mirsky AF, Lochhead SJ, Jones BP, Kugelmass S, Walsh D, Kendler KS: On familial factors in the attentional deficit in schizophrenia: A review and report of two new subject samples. J Psychiatric Res 26:383-403, 1992

28. Mirsky AF, Duncan CC: Behavioral and electrophysiological studies of absence epilepsy, in Avoli M, Gloor P, Kostopoulos G (eds): Generalized Epilepsy: Neurobiological Approaches, chap 5. Boston, Birkhauser, 1990, pp 254-269

29. Wechsler D: The Wechsler Intelligence Scale for Children, revised. New York, The Psychological Corporation, 1974

30. Grant DA, Berg EA: A behavioral analysis of degree of reinforcement and ease of shifting to new responses in a Weigl-type card-sorting problem. J Exp Psychol 38:404-411, 1948 
31. Berg EA: A simple objective technique for measuring flexibility in thinking. J Gen Psychol 39:15-22, 1948

32. Milner B: Effects of different brain lesions on card sorting. Arch Neurol 9:90-100, 1963 1965

33. Talland GA: Deranged Memory. New York, Academic Press,

34. Rosvold HE, Mirsky AF, Sarason I, Bransome ED, Beck LN: A continuous performance test of brain damage. J Consult Psychiatry 20:343-350, 1956

35. Mirsky AF, Cardon PV: A comparison of the behavioral and physiological changes accompanying sleep deprivation and chlorpromazine in man. Electroencephalogr Clin Neurophysiol 14:1-10, 1962

36. Mirsky AF, Van Buren JM: On the nature of the "absence" in centerncephalic epilepsy: A study of some behavioral, electroencephalic and autonomic factors. Electroencephalogr Clin Neurophysiol 18:334348,1965

37. Matier K, Halperin JM, Sharma V, Newcorn JH, Sathaye N: Methylphenidate response in aggressive and nonaggressive ADHD children: Distinctions on laboratory measures of symptoms. J Am Acad Child Adolesc Psychiatry 31:219-225, 1992

38. Seashore CB, Lewis C, Saltveit JG: Seashore Measures of Musical Talent: Manual. New York, Psychological Corporation, 1960

39. Milner B: Visually-guided maze learning in man: Effects of bilateral hippocampal, bilateral frontal, and unilateral cerebral lesions. Neuropsychologia 3:317-338, 1965

40. Streissguth AP, Barr HM, Sampson PD, Bookstein FL, Darby BL: Neurobehavioral effects of prenatal alcohol. Part I. Research strategy. Neurotoxicol Teratol 11:461-476, 1989

41. Sampson PD, Streissguth AP, Barr HM, Bookstein FL: Neurobehavioral effects of prenatal alcohol. Part II. Partial least squares analysis. Neurotoxicol Teratol 11:477-491, 1989

42. Streissguth AP, Bookstein FL, Sampson PD, Barr HM: Neurobehavioral effects of prenatal alcohol. Part III. PLS analyses of neuropsychologic tests. Neurotoxicol Teratol 11:493-507, 1989

43. Gray JK, Streissguth AP: Memory deficits and life adjustment in adults with fetal alcohol syndrome: A case control study. Alcohol Clin Exp Res 14:294, 1990

44. Blanchard BA, Riley EP, Hannigan JH: Deficits on a spatial navigation task following prenatal exposure to ethanol. Neurotoxicol Teratol 9:253-258, 1987

45. Ketterlinus RD, Bookstein FL, Sampson PD, Lamb ME: Partial least squares analysis in developmental psychopathology. Dev Psychopathol 1:351-371, 1989

46. Wold H (ed): Theoretical Empiricism: A General Rationale for Scientific Model Building. New York, Paragon House, 1989

47. Bookstein FL: The elements of latent variable models: A cautionary lecture, in Lamb M, Brown AL, Rosoff B (eds): Advances in Developmental Psychology, vol 4. Hillsdale, NJ, Lawrence Erlbaum Associates, 1986, pp 203-230

48. Becker RA, Chambers JM, Wilks AR: The New S Language: A Programming Environment for Data Analysis and Graphics. Pacific Grove, CA, Wadsworth, Brooks/Cole Advanced Books, Software, 1988

49. Statistical Sciences, Inc.: S-PLUS User's Manual, version 3.0. Seattle, WA, 1991

50. Bookstein FL, Sampson PD, Streissguth AP, Barr HM: Measuring "dose" and "response" with multivariate data using partial least squares techniques. Commun Statist 19:765-804, 1990

51. Friedman JH: A Variable Span Smoother. Technical Report no. 5. Palo Alto, CA, Stanford University, Laboratory for Computational Statistics, Department of Statistics, 1984

52. Streissguth AP, Barr HM, Sampson PD, Darby BL, Martin DC: IQ at age four in relation to maternal alcohol use and smoking during pregnancy. Dev Psychol 25:3-11, 1989

53. Barr HM, Streissguth AP, Darby BL, Sampson PD: Prenatal exposure to alcohol, caffeine, tobacco and aspirin: Effects on fine and gross motor performance in 4-year-old children. Dev Psychol 26:339348,1990
54. Streissguth AP, Barr HM, Sampson PD: Moderate prenatal alcohol exposure: Effects on child IQ and learning problems at age 7 1/2 years. Alcohol Clin Exp Res 14:662-669, 1990

55. O'Dougherty M, Nuechterlein KH, Drew B: Hyperactive and hypoxic children: Signal detection, sustained attention, and behavior. J Abnorm Psychol 93:178-191, 1984

56. Swanson HL: A developmental study of vigilance in learningdisabled and nondisabled children. I Abnorm Child Psychol 11:415429,1983

57. Milner B: Memory, in Weiskrantz L (ed): Analysis of Behavioral Change. New York, Harper \& Row, 1968, pp 328-356

58. Milner B: Some effects of frontal lobectomy in man, in, Warren JM, Akert K (eds): The Frontal Granular Cortex and Behavior. New York, McGraw Hill, 1964, pp 313-334

59. van Zomeren $\mathrm{AH}$, Brouwer WH: Head injury and concepts of attention, in Levin HS, Grafman J, Eisenberg HM (eds): Neurobehavioral Recovery from Head Injury. New York, Oxford University Press, 1987, pp 398-415

60. Stuss DT, Stethem LL, Hugenholtz H, Picton T, Pivik J, Richard MT: Reaction time after head injury: Fatigue, divided and focused attention, and consistency of performance. J Neurol Neurosurg Psychiatry $52: 742-748,1989$

61. Cohen NJ, Douglas VI: Characteristics of the orienting response in hyperactive and normal children. Psychophysiology 9:238-245, 1972

62. Sroufe LA, Sonies BC, West WD, Wright FS: Anticipatory heart rate deceleration and reaction time in children with and without referral for learning disability. Child Dev 44:267-273, 1973

63. Phillips DE, Krueger SK: Effects of combined pre-and postnatal ethanol exposure (three trimester equivalency) on glial cell development in rat optic nerve. Int J Dev Neurosci 10:197-206, 1992

64. Phillips DE, Krueger SK, Rydquist JE: Short- and long-term effects of combined pre- and postnatal ethanol exposure (three trimester equivalency) on the development of myelin and axons in rat optic nerve. Int J Dev Neurosci 9:631-647, 1991

65. Little RE, Uhl CN, Labbe RF, Abkowitz JL, Phillips EL: Agreement between laboratory tests and self-reports of alcohol, tobacco, caffeine, marijuana and other drug use in postpartum women. Soc Sci Med 22:91-98, 1986

66. Day NL, Robles N, Richardson G, Geva D, Taylor P, Scher M, Stoffer D, Cornelius M, Goldschmidt L: The effects of prenatal alcohol use on the growth of children at three years of age. Alcohol Clin Exp Res $15: 67-71,1991$

67. Goodlett CR, Kelly SJ, West JR: Early postnatal alcohol exposure that produces high blood alcohol levels impairs development of spatial navigation learning. Psychobiology 15:64-74, 1987

68. Kelly SJ, Goodlett CR, Hulsether SA, West JR: Impaired spatial navigation in adult female but not adult male rats exposed to alcohol during the brain growth spurt. Behav Brain Res 27:247-257, 1988

69. Bonthius DJ, West JR: Alcohol-induced neuronal loss in developing rats: Increased brain damage with binge exposure. Alcohol Clin Exp Res 14:107-118, 1990

70. Pierce DR, West JR: Blood alcohol concentration: A critical factor for producing fetal alcohol effects. Alcohol 3:269-272, 1986

71. Pierce DR, West JR: Alcohol-induced microencephaly during the third trimester equivalent: Relationship to dose and blood alcohol concentration. Alcohol 3:185-191, 1986

72. Kelly SJ, Pierce DR, West JR: Microencephaly and hyperactivity in adult rats can be induced by neonatal exposure to high blood alcohol concentrations. Exp Neurol 96:580-593, 1987

73. Schenker S, Becker HC, Randall CL, Phillips DK, Baskin GS, Henderson GI: Fetal alcohol syndrome: Current status of pathogenesis. Alcohol Clin Exp Res 14:635-647, 1990

74. Streissguth AP, Barr HM, Martin DC, Herman CS: Effects of maternal alcohol, nicotine and caffeine use during pregnancy on infant mental and motor development at 8 months. Alcohol Clin Exp Res $4: 152-164,1980$

75. Streissguth AP, Barr HM, Martin DC: Alcohol exposure in utero 
and functional deficits in children during the first four years of life, in Porter R, O'Connor M, Whelan J (eds): CIBA Foundation Symposium 105: Mechanisms of Alcohol Damage in Utero. London, Pitman, 1984 , pp 176-196

76. Fried PA, Watkinson B: 12 - and 24-month neurobehavioral follow-up of children prenatally exposed to marijuana, cigarettes and alcohol. Neurotoxicol Teratol 10:305-313, 1988

77. Fried PA, Watkinson B: 36- and 48-month neurobehavioral follow-up of children prenatally exposed to marijuana, cigarettes, and alcohol. J Dev Behav Pediatr 11:49-58, 1990
78. Russell M, Czarnecki DM, Cowan R, McPherson E, Mudar P: Measures of maternal alcohol use as predictors of development in early childhood. Alcohol Clin Exp Res 15:991-1000, 1991

79. Coles CD, Brown RT, Smith IE, Platzman KA, Erickson S, Falek A: Effects of prenatal alcohol exposure at school age. I. Physical and cognitive development. Neurotoxicol Teratol 13:357-367, 1991

80. Cahalan D, Cissin IH, Crossley HM: American drinking practices: A national study of drinking behavior and attitudes (Monograph no. 6). New Brunswick, NJ, Rutgers Center for Alcohol Studies Publications, 1969

Dr. Donald Gallant, Professor Emeritus, Department of Psychiatry/Neurology, Tulane University Medical Center, New Orleans, is recognized as an international scholar in Neuropsychiatric disorders and in Alcoholism. He has received numerous awards including the Gold Achievement Award from the American Psychiatric Association, teaching awards, served on Editorial Boards, authored over 200 scientific articles and until now has served as Editor of the "Current Literature Reviews and Critiques" of Alcoholism Clinical and Experimental Research.

Dr. Gallant has now relinquished this position, and the Journal and the Research Society on Alcoholism wishes to express its deep appreciation to him. His concise, clearly defined summaries have been of interest to all the Journal readers. His contributions deserve our praise and thanks. We shall miss his contributions. 